\title{
Monitoring Opioid Adherence in Chronic Pain Patients: Tools, Techniques, and Utility
}

Laxmaiah Manchikanti, MD1, Sairam Atluri, MD², Andrea M. Trescot, MD³, and James Giordano, $\mathrm{PhD}^{4}$

From: ${ }^{1}$ Pain Management Center of Paducah, Paducah, KY; ${ }^{2}$ Tri-state Pain Management, Loveland, $\mathrm{OH}$ 3 University of Florida, Gainesville FL; and ${ }^{4}$ Georgetown University Medical Center, Washington, DC

Dr. Manchikanti is Medical Director of the Pain Management Center of Paducah, Paducah, KY and Associate Clinical Professor of Anesthesiology and Perioperative Medicine, University of Louisville, KY

Dr. Atluri, Tri-State Pain Management, Loveland, $\mathrm{OH}$

Dr. Trescot is the Director of the Pain Fellowship Program at the University of Florida and the Malcolm Randall VA Medical Center, Gainesville, FL.

Dr. Giordano is Samueli-Rockefeller Professor, Department of Medicine, Schola in Residence, Center for Clinical Bioethics Georgetown University Medical Center, Washington, D.C. and Director of the Center

for Brain, Mind, and Healing Research, Samueli Institute, Alexandria, VA

Address correspondence: Laxmaiah Manchikanti, M.D. 2831 Lone Oak Road Paducah, Kentucky 42003 E-mail:drlm@thepainmd.com

Disclaimer: Funded in part by a grant from the Laurance S. Rockefeller Trust, and by the Center for Brain, Mind, and Healing Research, Samueli Institute and the Department of Medicine, Georgetown University Medical Center. Conflict of interest: None.

Free full manuscript: www.painphysicianjournal.com
Opioids are important, if not essential, agents in treating certain types of chronic pain. However, the prevalence of drug misuse, abuse, and addiction has fostered considerable consternation among physicians, who may hesitate to prescribe these medications both due to concern for patients (misuse, abuse, and addiction), and fears of prosecution and/or professional sanction. Such practice may reflect

1) inadequate knowledge about patients' susceptibility to, or current drug misuse or abuse;

2) lack of familiarity with extant assessments and/or regulations, and/or

3) an unanticipated reaction to existing guidelines, policies or laws.

We posit that assessing patients' predisposition to, and patterns of, drug misuse/abuse is a vital first step toward establishing and maintaining the safe and effective use of opioid analgesics in the treatment of chronic pain. Adherence monitoring is critical to identify patients' prior and current drug use, establish treatment basis, and evaluate compliance, so as to avoid misuse and abuse, and ensure sound and proper pain management.

This paper provides a review of the numerous monitoring approaches that have been described in the literature and addresses the benefits and limitations of these techniques and tools. The complex nature of the problem of drug misuse and abuse is discussed, and while no single monitoring technique can fully address this complex issue, we describe how multiple approaches to adherence monitoring may be employed to sustain the prudent use of opioids for the treatment of chronic pain.

Key words: Opioids, adherence monitoring, drug abuse, non-compliance, misuse, addiction, urine drug testing

Pain Physician 2008; 11:S155-S180 here is abundant evidence to demonstrate that opioids may be a legitimate, if not the legitimate, agent(s) of choice for treating certain types of chronic pain. Yet, issues of drug abuse and diversion, inapt prescription of opioids, and soaring medical costs all impact the treatment of pain, and as a result, the prevalence of chronic pain continues to rise and remains an ever-prominent 
public health concern in the United States. In recent years, the expanded use of opioid analgesics for the treatment of chronic non-cancer pain, and the introduction of high-dose, extended-release opioid formulations have both improved access to these drugs and increased misuse, abuse, and diversion (1-18). Federal, state, and local governments; professional associations; as well as pharmaceutical companies, physicians, and the public all share responsibility for preventing abuse of controlled prescription drugs (6). The challenge is to eliminate or significantly curtail abuse of controlled prescription drugs while still assuring the proper treatment of those patients who can be helped by these medications. We posit that information is crucial to 1) allow accurate clinical and administrative (i.e. legal and governmental) assessment of the true nature and scope of prescription (and illicit) drug abuse, 2) provide physicians insight to patients' patterns of drug use and compliance so as to direct the type and conduct of treatment that can and should be provided, and thus 3 ) insure the safe, ethical, and legally sound practice of medicine. Adherence monitoring has been shown to be a useful approach to acquiring information from biological, psychological, and social domains that can assist in identifying and/or predicting patterns of drug use, compliance, misuse, and abuse (2).

A number of techniques, instruments, and tools have been described to monitor controlled substance use and abuse. Given that multiple factors may be involved in drug misuse and abuse, no single instrument or assessment method has universal evaluative or predictive utility. Thus, multiple techniques and tools are available and have been used to monitor adherence. These include various screening tests, urine drug testing, and prescription monitoring programs. Each of these methods has some relative validity and utility in assessing patterns of drug use, misuse, abuse, and/or the potential or occurrence of addiction. In light of this, it is important for the clinician to

1) determine whether $s /$ he wishes to assess compliance, misuse, abuse, and/or addiction, so that

2) the appropriate evaluative method(s) can be employed.

Crucial to this process is that each of these terms (and conditions) must be operationally defined, as these are frequently used inter-changeably, inappropriately, and incorrectly.

\section{Definitions}

Medical professionals frequently disagree on a variety of clinical issues based on their education, specialty orientation, personal needs, economics, and the personal and professional biases these factors incur. While prescription drug abuse has been a longstanding concern, opinions on what is considered misuse and abuse continue to evolve and differ based upon scientific, legal, political and social orientation. Thus, the terms drug misuse, abuse, and illicit drug use can mean different things to different people even within the same specialties and organizations, both within and outside of the scientific community. However, such distinct definitions are not merely semantic, since they can be used to formulate guidelines and policies describing proper use, and the sanctions and penalties for misuse. For example, in a 2006 National Survey on Drug Use and Health (NSDUH), the Substance Abuse and Mental Health Services Administration (SAMHSA) defined non-medical substance use as that which is engaged without a prescription and/or for the experience or feeling produced by the agent (7). In contrast, the Institute of Medicine has defined drug "abuse" as any harmful use, irrespective of whether the behavior occurs within the parameters of prescription or meets the criteria for disorder as established in the American Psychiatric Association's Diagnostic and Statistical Manual, fourth edition text revised (DSM-IVTR) $(8,19)$.

This latter distinction reflects the American Psychiatric Association's characterization of abuse as a "maladaptive pattern of substance use, leading to clinically significant impairment or distress as manifested by one or more of the following, occurring within a 12-month period: recurrent substance use, resulting in a failure to fulfill major obligations at work, school, or home; recurrent substance use in situations in which it is physically hazardous; recurrent substance-related legal problems; or continued substance use despite having persistent or recurrent social or interpersonal problems caused or exacerbated by the effects of the substance" (20). As well, the American Psychiatric Association defines substance dependence disorder as a more severe form of substance abuse. To meet the criteria for substance abuse, 3 or more diagnostic variables (out of a total of 7), occurring within a 12-month period, must be met. Those variables include a persistent desire or 
unsuccessful efforts to reduce or control substance use, devotion of time and activities to obtain the substance, tolerance, and continued (need for and desire to) use of the substance despite knowledge of having persistent or recurring physical or psychological problem(s) caused or exacerbated by the substance.

Using a set of criteria from the International Classification of Diseases evolving since 1952, the World Health Organization (WHO) noted the potential for confusion between the terms physical dependence and drug dependence, and substituted the term withdrawal syndrome for physical dependence in 1993 (21). In 1998, the expert committee replaced the term drug dependence with dependence syndrome, but in so doing, simply redesignated the original definition without revision(s). Consequently, the terms "dependence syndrome" and "withdrawal syndrome" are identical clinical entities under the current WHO nomenclature. The dependence syndrome is defined as "...a state, psychic and sometimes also physical, resulting from the interaction between a living organism and a drug, characterized by behavioral and other responses that always include a compulsion to take the drug on a continuous or periodic basis in order to experience its psychic effects, and sometimes to avoid the discomfort of its absence. Tolerance may or may not be present ..." (21). The withdrawal syndrome, defined as "...a cluster of physiological, behavioral, and cognitive phenomena of variable intensity, in which the use of a psychoactive drug(s) takes on a high priority. The necessary descriptive characteristics are preoccupation with a desire to obtain and take the drug and persistent drug-seeking behavior. Determinants and problematic consequences of drug dependence may be biological, psychological, or social, and usually interact" was substituted for physical dependence (22).

The International Classification of Diseases (ICD10) (24) uses the term "dependence syndrome" when at least 3 of the 6 features are identified with dependence syndrome. Of the 6 criteria, 4 relate to compulsivity:

1) a persistent, strong desire to take a drug,

2) difficulty controlling drug use,

3) impairment of function, including neglect of pleasures and interests, and

4) harm to self.

The remaining 2 factors relate to the evidence of withdrawal symptoms and tolerance. Of note is that neither the American Psychiatric Association nor the ICD explicitly address the term (or concept) of addiction.

The Controlled Substance Act defined addiction as the habitual use of any drug (substance or act) so as to endanger the public morals, health, safety, or welfare, or the use of such drugs in ways that reflects a diminished power of self-control or judgment (23).

A somewhat more detailed definition is afforded by consensus description(s) that recognize the biological and environmental variables that can influence addiction (25); this definition refers to "...a primary, chronic, neurobiologic disease, with genetic, psychosocial, and environmental factors influencing its development and manifestations. It is characterized by behaviors that include one or more of the following: impaired control over drug use, compulsive use, continued use despite harm, and craving." Physical dependence was defined as "a state of adaptation that is manifested by a drug class with a specific withdrawal syndrome that can be produced by abrupt cessation, rapid dose reduction, decreasing blood level of the drug, and/or administration of an antagonist." Tolerance was defined as "a state of adaptation in which exposure to a drug induces changes that result in a diminution of one or more of the drug's effects over time." Taken together definitions of misuse, abuse, tolerance, dependence, and addiction are useful in describing the nature of the disorders and their signs and symptoms.

In this manuscript, we will classify

1) non-medical use and abuse when agents are used for non-medical purposes beyond the scope of the prescription, and

2) improper medical use when agents are used in a manner inconsistent with the prescription or have been improperly prescribed, provided, or obtained.

Obviously both non-medical and improper medical use are important clinical, medico-legal, and social problems. Thus, it becomes critical for clinicians to take a proactive role not only in ensuring proper and prudent prescription of opioids, but to assume increased responsibility for ongoing assessment and management of prescription use (compliance, effect) as

1) stewards of knowledge,

2) consistent with the reciprocal fiduciary of the medical relationship, and

3) reflective of the primacy of patients' best interests. 


\section{Screening Tests}

Screening tests (for prescription and illicit drugs) may be employed at initial evaluation and as necessary or desired thereafter. While there are numerous descriptions of screening tests in the literature, a singular or uniformly accepted screening instrument that can be broadly used in current practice is lacking. Various authors have reviewed screening tests available to identify patterns of prescription abuse or addiction (26-28). Savage (26) described patterns that may suggest addiction during opioid therapy for pain based on the 3 " C's" - Continued use of drugs despite adverse consequences or harm, Compulsive use, and Craving, along with differential diagnosis of behaviors suggestive of addiction.

Smith and Kirsh (27) described the utility of multiple brief screening instruments, including the Screening Tool for Addition Risk (STAR) (29), Drug Abuse Screening Test (DAST) (30), Screener and Opioid Assessment for Patients with Pain (SOAPP) (31), Pain Assessment and Documentation Tool (PADT) $(32,33)$, and the Opioid Risk Tool (ORT) (34) that could be employed to evaluate prescription misuse or abuse during longterm opioid therapy for pain.

A literature review by Højsted and Sjøgren (28) evaluated the utility of several screening instruments including CAGE Questionnaire (35), Prescription Opiate Abuse Checklist (36), Short Michigan Alcoholism Screening Test (Also Including Drugs) (SMAST-AID) (37), Prescription Drug Use Questionnaire (PDUQ) (38), Attitude and Behavior Questionnaire (39), Substance Use Questionnaire (40-42), the Screening Tool for Addiction Risk (STAR) (29), the Screener and Opioid Assessment for Pain Patients (SOAPP) (31), and various other tests (43-45). Tests not included in the above reviews also have been published (46-51).

Each of these tools has been shown to have potential benefits and limitations that could dictate effectiveness and utility in various pain management scenarios. The SOAPP consists of 24 items that can be answered on a 5-point scale. The questionnaire was administered to 175 patients with chronic non-cancer pain and re-administered to 95 patients after 6 months. The data suggested that a score of 7 or higher might be a reasonable choice for SOAPP cut-off (31). Akbik et al (52) evaluated the reliability and validity of SOAPP as a measure of risk of abuse for patients taking opioid medication. It was shown that patients in the high-risk group were younger, more likely to be asked to give a urine screen, and had more abnormal urine screens compared to those in the low-risk group. This evaluation identified a combined factor analysis of 5 factors that were predicitive of abuse; these were

1) history of substance abuse,

2) legal problems,

3) medication craving,

4) heavy smoking, and

5) mood swings

These factors provided preliminary support for the internal reliability and predictive validity of the SOAPP. However, this has not been replicated. Thus, the long-term, pragmatic utility and applicability of the SOAPP (in multiple settings) remains undefined.

Butler et al (46) developed and validated a Current Opioid Misuse Measure (COMM) consisting of 40 items, of which 17 appeared to adequately measure aberrant drug-taking behavior. Initially, it was found that the COMM had internal consistency and testretest reliability. However, while this proposed test showed promise as a brief, self-report measure of current aberrant drug-related behavior, the utility of the COMM has not been replicated with more diverse subjects in a variety of clinical settings. Thus, the actual long-term reliability of this test remains unknown.

Adams et al (43) developed the Pain Medicine Questionnaire (PMQ) to assess risk for aberrant use of opioid medication. The PMQ consists of 26 items which reflect a range of potentially dysfunctional attitudes and behaviors. Responses are evaluated on a 5-point scale. Upon evaluation, it was concluded that patients falling in the lower third of scores constituted the lowrisk group and those falling in the highest third of the scores constituted the high-risk group. Holmes et al (53) evaluated the PMQ using a larger sample to replicate the findings and examine the relationship between PMQ scores and various treatment outcomes. They administered the PMQ in 271 newly evaluated chronic pain patients who were subsequently reevaluated both immediately post-treatment and at 6 months following discharge. These subgroups were classified according to the lowest, middle, and highest third of PMQ total scores. It was shown that the highest PMQ group was 2.6 times more likely to have an identifiable substance abuse problem, 3.2 times more likely to request early refills of prescription medication, and 2.3 times more likely to attrite from treatment, as compared to the low PMQ group. Further, patients in the high scores group also had diminished biopsychosocial functioning. In addition, it was shown that at 6 months post discharge, those patients who completed 
the program evidenced a significant decrease in PMQ scores over time relative to those patients who were either unsuccessfully discharged from the program, or who attrited. Even though Holmes et al (53) presented follow-up evaluation of PMQ, the wide variety of patients and clinical circumstances were such that further research is needed to fortify the replicability and validity of the PMQ as a broad-use tool. Further, while seemingly effective, the screening questionnaire can take a significant amount of time to complete and evaluate, and this may limit its use. Consequently, the general applicability of this test is still preliminary and additional assessment is required to better define its potential.

Miotto et al (38) developed the Prescription Drug Use Questionnaire (PDUQ), a 42-item instrument to access patterns of prescription drug compliance in chronic pain patients. The screening tool evaluated the pain condition, opioid use patterns, social and family factors, family history of pain and substance abuse syndromes, patient history of substance abuse, and psychiatric history. The PDUQ takes approximately 20 minutes to administer. The questionnaire was evaluated by Compton et al (48) in 52 patients with chronic non-malignant pain in a university-based pain center. They identified certain drug seeking behaviors (more commonly noted in subjects with addictive disorder) such as having more than 1 prescription provider, increasing prescribed analgesic dose or frequency of use, requesting early prescription refills, and obtaining analgesics from emergency rooms. They also identified 3 pre-screening indicators as firm predictors of addictive disorder, namely 1) the tendency to increase analgesic dose or frequency of use, 2) preference for route of administration, and 3) a self regard as "addicted." However, it has been noted that these key criteria have not been completely established nor validated to be wholly predictive of addictive disorder or tendency.

Friedman et al (29) developed the Screening Tool for Addiction Risk (STAR), that utilizes 14 true-or-false questions. This tool was validated in chronic pain patients with and without addiction. Questions related to addiction included prior treatment in a drug rehabilitation facility, nicotine use, self-assessment of excessive nicotine use, and treatment in another pain clinic. It was found that history of treatment in a drug or alcohol rehabilitation facility was a significant predictor of ongoing addiction, with a positive predictive value of $93 \%$ and a negative predictive value of $5.9 \%$.
However, despite these results, this study was limited in scope and application, and these results have not been replicated.

Webster and Webster (34) formulated a brief screening instrument, known as Opioid Risk Tool (ORT), for use in chronic pain patients. The ORT addresses age, personal and family history of substance abuse, history of preadolescent sexual abuse, and presence of certain psychological conditions. Patients with scores of 0 to 3 are considered low risk for opioid misuse/abuse, scores of 4 to 7 are considered moderate risk, and scores of 8 or higher are considered to reflect high risk. In a follow-up study, 185 patients were monitored for aberrant drug use-related behaviors for 12 months after their initial visits. The ORT was shown to be sensitive and specific for determining which individuals were at risk for abuse of opioid drugs. Still, the universal applicability of this tool remains to be shown, as these results have not yet been replicated.

Passik et al (39) developed the Attitude and Behavior Questionnaire (ABQ), which addressed issues such as medication use, present and past drug abuse, patient's beliefs about the risk of addiction in the context of pain treatment, and aberrant drug-taking attitudes and behaviors. The ABQ was piloted in 52 cancer patients and 111 patients with HIVIAIDS. Results were presented as percentages of attitudes and behaviors occurring in these populations; however, no attempt was made to validate whether these percentages were actually reflective or predictive of drug use, and the results continue to remain preliminary.

Passik et al $(32,33)$ also presented the Pain Assessment and Documentation Tool (PADT), a simple charting device that focuses on key outcomes and provides a consistent approach to documenting compliance and progress in pain management therapy over a period of time. A 2-sided chart that can be readily included in the patient's medical record, the PADT was designed to be, and apparently functions as, a pragmatic tool that is easily adaptable to a variety of clinical situations (27).

The Substance Use Questionnaire developed by Cowen et al was evaluated in 168 chronic pain patients, and 39 street heroin users (40-42). The instrument has been shown to reliably differentiate pain from addicted patients, and perhaps may establish some predictive indices of prescription use between these groups. However, while this may be valid in substance abuse settings, this test may be less than applicable in chronic pain care settings. 
Elander et al (44) utilized a semi-structured interview to address and differentiate between pain-related symptoms and those of substance dependence and abuse according to DSM-IV criteria. Dependence and/ or abuse is classified as present or absent, and classified as pain- or non pain-related. While these distinctions would appear to be relevant to differentiating potential pain-related drug escalation and/or misuse from a primary addictive or substance abuse disorder, the actual clinical applicability of this test is not yet known.

Chabal et al (36) developed criteria to evaluate prescription opiate abuse in patients with chronic non-malignant pain. They attempted to distinguish the chronic pain patient who is misusing prescription opiate medications from the person whose opiate use is unrelated to a chronic pain condition. They demonstrated that a patient may qualify as a prescription opiate abuser by meeting 3 or more of the following criteria:

1) overwhelming focus on drug-related issues during pain clinic visits that persist beyond the third clinic treatment session;

2) a pattern of (3 or more) early refills, or escalating drug use in the absence of an acute change in the medical condition;

3) multiple telephone calls or visits with requests for more opiates, early refills or problems associated with the opiate prescription;

4) reports of lost, spilled, or stolen medications; and

5) obtaining opiates from multiple providers, emergency rooms, or illegal sources.

Interestingly, it was concluded that past opiate or alcohol abuse, depressive symptoms, the perceived need for opiates, and/or pain levels on clinic admissions failed to predict pattern(s) of opiate abuse. While the authors believed that the criteria can be used in a clinical setting, certain limitations may restrict its reliability. Namely, the assessment was performed in a specific clinical population of veterans that were referred to the pain clinic from primary care clinics solely for reasons related to their use of opiates and/or meeting specific psychiatric criteria. Obviously, to best evaluate the utility of these criteria, a broader population sample would need to be employed.

Michna et al (45) evaluated the usefulness of a questionnaire for chronic pain patients in a hospitalbased pain management program who had been, or were about to be, prescribed opioids. The patients were classified as high- or low-risk based upon their responses to questions about past problems with drug or alcohol use/abuse, their history of legal problems, and comorbid factors including mental health problems, smoking, motor vehicle accidents, and adverse drug effects. It was shown that the most predictive variables for high risk of opioid misuse were a positive urine screen, a higher required dose of opioid, and the need for a cigarette within the first hour of the day. However, these findings also have not been replicated, and the long-term reliability and applicability of this tool in multiple settings has not been determined.

One of the most useful tools to predict potential substance misuse in pain patients has been developed by Atluri and Sudarshan (47). This instrument was developed with the particular intent for use in interventional pain management settings, and identifies 6 clinical criteria as predictive factors for opioid misuse: 1) focus on opioids, 2) opioid overuse, 3) other substance use, 4) non-functional status, 5) unclear etiology of pain, and 6) exaggeration of pain. Atluri and Sudarshan (47) defined the constellation of inappropriate drug use as taking illicit drugs, presence of opioids other than those prescribed, refusal to provide urine samples for drug testing, and any evidence of tampering with the urine specimen.

These criteria were evaluated by Manchikanti et al $(54,55)$ using a prospective sample of 500 total patients from an interventional pain management setting, with 100 patients having a history of drug abuse, and 400 patients without a history of drug abuse. Drug abuse was defined as the misuse of controlled substances in a clinical setting, including obtaining controlled substances from other physicians or other identifiable sources, dose escalation, and/or violation of controlled substance agreements. The authors found that excessive opioid needs, deception to obtain, and prior intentional doctor shopping were $90 \%$ accurate in identifying/predicting drug abuse (with odds ratios greater than 100 , and $p$ values of 0.001 or less). Thus, it was concluded that this tool provides a simple, reliable, and cost-effective means of screening for drug abuse during the clinical evaluation of patients in interventional pain management settings.

Manchikanti et al (55) also evaluated variables contributing to, and predictive of, illicit drug use, and examined the reliability of the controlled substance abuse screening tool to identify such illicit drug use. Excessive opiate need, deception or lying to obtain controlled substances, current or prior intentional doctor shopping, and current or prior use of illicit drugs and de- 
nial accurately allowed identification of controlled substance abuse. However, these variables did not identify illicit drug use. Thus, when results are combined from both studies $(54,55)$, only current or prior use of illicit drugs and denial were indicative of the likelihood for illicit drug use. Manchikanti et al $(54,55)$ replicated the findings of Atluri and Sudarshan (47) in 2 studies. Of interest is that contrary to Atluri and Sudarshan (47), Manchikanti and co-workers $(54,55)$, and Chabal et al (36) concluded that past opiate or alcohol abuse, the perceived need for opiates, pain levels, and clinic admissions, and/or presence of depressive symptoms failed to predict the risk likelihood of opiate abuse.

Coambs et al (49) developed and validated the Screening Instrument for Substance Abuse Potential (SISAP) to quickly and accurately identify individuals with a possible substance abuse history, based on findings of the National Alcohol and Drug Use Survey $(n=$ 9915). The SISAP correctly classified $91 \%$ of substance abusers, and had a low rate of false-negatives; however, this was only a preliminary validation, and these results have not been replicated.

Wu et al (51), published a new clinician-administered instrument to measure inappropriate drug use in chronic pain patients. This brief, 20 -item instrument focuses on observable behaviors noted both during and between the clinic visits. The tool was validated in a population of 136 veterans, and it was was concluded that psychometric findings support its use as a viable assessment that can increase a provider's confidence in determination of appropriate versus inappropriate opioid use.
Savage (26) described multiple addiction-screening instruments that have been standardized and that are reasonably sensitive in identifying addictive disorders or problematic drug or alcohol use. Of these, three have been indicated to be appropriate for brief screening in clinical practice: the CAGE-AID Screen (35), the CyrWartman Screen (56), and the Skinner Trauma Screen (57). These questionnaires are listed in Table 1.

The CAGE (developed from the keywords - cut, annoy, guilty, eye - included in 4 questions used in the tool) was originally developed for alcohol use screening, and was subsequently adapted to assess (mis)use of other drugs. Two positive answers constitute a positive screen, although it has been suggested that using a criterion of 1 positive answer yields a better sensitivity (58). The Cyr-Wartman screen (56) is somewhat simpler, yet is considered to be equivalently sensitive and specific as the more widely used CAGE screen. Like the CAGE, the Cyr-Wartman screen was originally developed to assess alcohol misuse, even though in clinical practice, the words "all drugs" are often used to identify drug abuse and thus sustain its utility as an indicator of more general substance abuse.

Similarly, the Skinner Trauma history screen (57) is used to identify alcohol abuse, and while it has not been formally adapted to identify drug use problems, informal clinical adaptation toward this end is considered reasonable (26). It is important to note that all of these screening tools are not generally diagnostic, nor are they specific for drug misuse, abuse, or addiction, per se.

Savage (26) described behaviors suggestive of

Table 1. Questionnaires for 3 commonly used screens in addiction-screening.

\begin{tabular}{|l|l|l||}
\hline CAGE-AID & $\begin{array}{l}\text { Have you felt you ought to Cut down on your drinking or drug use? } \\
\text { Have people Annoyed you by criticizing your drinking and drug use? } \\
\text { Have you felt bad or Guilty about your drinking and drug use? } \\
\text { Have you ever had a drink or used drugs first thing in the morning to } \\
\text { steady your nerves or to get rid of a hangover (Eye-opener)? }\end{array}$ & $\begin{array}{l}\text { Two positive answers constitutes a } \\
\text { positive screen. }\end{array}$ \\
\hline Cyr-Wartman Screen & $\begin{array}{l}\text { Have you ever had a problem with alcohol (or drugs)? } \\
\text { When was your last drink (or drugs)? }\end{array}$ & $\begin{array}{l}\text { A positive screen that roughly } \\
\text { correlates with the CAGE in terms } \\
\text { of specificity and sensitivity is “yes" } \\
\text { and within 24 hours of the medical } \\
\text { appointment. }\end{array}$ \\
\hline Skinner Trauma History & $\begin{array}{l}\text { Since your 18th birthday, have you: } \\
\text { Had any fractures of dislocations to your bones or joints? } \\
\text { Been injured in a road traffic accident? } \\
\text { Injured your head? } \\
\text { Been injured in an assault or fight (excluding injuries during sports)? } \\
\text { Been injured after drinking? }\end{array}$ & $\begin{array}{l}\text { Two positive answers from 5 } \\
\text { questions constitute a positive } \\
\text { response. }\end{array}$ \\
\hline
\end{tabular}

Adapted from Savage (26) 
Table 2. Patterns suggesting addiction in chronic pain patients.

Adverse Consequences/harm due to use

Intoxicated/somnolent/sedated

Declining activity

Irritable/anxious/labile mood

Increasing sleep disturbance

Increasing pain complaints

Increasing relationship dysfunction

Impaired Control over use/Compulsive use

Reports lost or stolen prescriptions or medications

Frequent early renewal requests

Urgent calls or unscheduled visits

Abusing other drugs or alcohol

Cannot produced medications on request

Withdrawal noted at clinic visits

Observers report overuse or sporadic use

Preoccupation with use due to Craving

Frequently misses appointment unless opioid renewal expected

Does not try nonopioid treatments

Cannot tolerate most medications

Requests medications with high reward

No relief with anything except opioids

Any of these behaviors may occur from time to time in patients using opioids appropriately for pain relief or when pain is inadequately relieved. A pattern of these behaviors in the context of titrated pain therapy suggests the need for further evaluation.

Adapted from Savage (26) addiction (Table 2). However, any patient using opioid medications for pain may appear to manifest 1 or more of these behaviors from time to time, and a persistent pattern of such behaviors would merit further consideration by the prudent clinician to discern whether these are, in fact, reflective of inappropriate prescription drug use.

\section{Assessment of Potentially Related Co-Factors}

Portenoy (59) compiled a list of aberrant drug-related behaviors, which were divided into 2 risk categories (i.e., more predictive of addiction and less predictive of addiction, Table 3) and there is considerable research devoted to profiling the psychological and behavioral characteristics of chronic pain patients in an attempt to accurately identify and predict potential (for) substance abuse, and develop strategies and tactics to effectively co-manage psychological and physical symptoms and the combined effects of disability $(7,9,10,34,46,60-70)$. Schieffer et al (50) assessed the influence of beliefs about medication, symptom severity, disability, mood, and psychiatric history on opiate misuse behaviors in chronic pain patients. It was shown that patients with a history of substance abuse (compared to those without) showed greater overall medication misuse. Misusers more strongly believed both in the potential for opioid addiction, and that higher doses of opoids

Table 3. Drug use behaviors relatively more predictive and less predictive of addiction.

\begin{tabular}{|c|c|}
\hline Probably more predictive of addiction & Probably less predictive of addiction \\
\hline $\begin{array}{l}\text { - Selling prescription drugs } \\
\text { - Prescription forgery } \\
\text { - Stealing or "borrowing" drugs from others } \\
\text { - Injecting oral formulations } \\
\text { - Obtaining prescription drugs from nonmedical sources } \\
\text { - Concurrent abuse of alcohol or illicit drugs } \\
\text { - Multiple dose escalation or other noncompliance } \\
\text { - } \text { with therapy despite warnings } \\
\text { - Rultiple episodes of prescription "loss" } \\
\text { from emergency rooms without informing prescriber or } \\
\text { after warnings to desist } \\
\text { - Evidence of deterioration in the ability to function at work, } \\
\text { in the family, or socially that appears to be related to drug use } \\
\text { - Repeated resistance to changes in therapy despite clear evidence } \\
\text { of adverse physical or psychological effects from the drug }\end{array}$ & $\begin{array}{l}\text { - Aggressive complaining about the need for more drugs } \\
\text { - Drug hoarding during periods of reduced symptoms } \\
\text { - } \text { Opequesting specific drugs } \\
\text { - Unsanctioned dose escalation or other noncompliance with } \\
\text { therapy on } 1 \text { or } 2 \text { occasions } \\
\text { - Unapproved use of the drug to treat another symptom } \\
\text { - Reporting psychic effects not intended by the clinician } \\
\text { - Resistance to a change in therapy associated with "tolerable" } \\
\text { adverse effects with expressions of anxiety related to the return } \\
\text { of severe symptoms }\end{array}$ \\
\hline
\end{tabular}

Adapted from Portenoy (59) 
to mitigate their pain than others, yet these patients also had greater belief in opioid effectiveness and the importance of free access. Both anxiety and substance abuse history were also shown to be related to medication misuse. However, the study population was from a large urban VA medical center, and included a highly disproportionate number of male patients with low socioeconomic status, with high rates of substance abuse, and psychiatric co-morbidity. Thus, while these factors limit the generalizability of findings, they also strengthen the need to better understand the co-morbidity of, and relationship between, pain, psychiatric, and substance abuse disorders.

The NSDUH survey of 2006 (7) evaluated the prevalence of serious psychological distress (SPD) and major depressive episode (MDE) and the association of these problems with substance use, dependency, and/or abuse. It was shown that persons with a history of at least 1 major depressive episode within the past year were significantly more likely to have used illicit drugs during that time period compared to those persons without a major depressive episode $(27.7 \%$ versus $12.9 \%)$, and substance dependence or abuse was more prevalent among persons with a major depressive episode than among non-depressed persons (24.3\% versus $8.1 \%$ ). Similarly, serious psychological distress was highly correlated to substance dependence or abuse (22.3\%). Regier et al (64) showed that patients with a lifetime mental disorder present more than twice the risk of having an alcohol disorder, and over 4 times the risk of having (another) substance abuse disorder. Webster and Webster (34) have shown that depression is a risk factor for opioid abuse, although Ives et al (66) failed to reveal a direct correlation between depression and opioid misuse. Manchikanti et al (9) reported higher current illicit drug use in men with somatization disorder $(22 \%)$ than men without somatization disorder $(9 \%)$, and demonstrated depression to be a variable in drug misuse (10). According to Dersh et al (67) chronic pain patients are 10.2 times more likely than persons in the general population to have a major Axis I psychiatric disorder (including drug abuse and alcohol abuse/dependence, as well as major depression, dysthymia, and any anxiety disorder). Their study showed that drug abuse and dependence were present in $10.7 \%$ of the patients, while Schieffer et al (50) showed a correlation only between anxiety and medication misuse. Chabal et al (36) concluded that depressive symptoms alone were insufficient to identify or predict the potential for opioid abuse in pain patients.
Given our hypothesis that certain forms of chronic pain, psychopathology, and substance misuse/abuse may be components of a spectrum disorder in which underlying genotype(s) are pre-dispositional to endoand exo-phenotypes that are differentially expressed as a consequence of environmental interactions (9), then it would be expected that 1) this spectrum would likely be expressed with variable intensity (i.e., not all syndromes, signs, and/or symptoms expressed in all patients), 2) certain syndromes represent a greater expression of the underlying spectrum than others, 3 ) the combination of certain signs and symptoms need not be directly associated with a particular syndrome, but could occur as a result of some other condition, and 4) the expression of such symptoms do not necessarily indicate that the entire constellation of spectrum features will occur. In other words, while pain, and certain psychopathologies (such as anxiety and/or depressive disorder, and certain forms of substance abuse) can reflect a biological predisposition, and therefore can, and sometimes may, co-occur (as part of a genotypicallylinked spectrum disorder), the differential expression of these conditions depends upon 1) genotypic-phenotypic matching, 2) environmental influences, and 3) the extent to which these phenotypes are manifested as syndromes along the underlying pathologic spectrum/continuum.

In this way, it is important to consider what other (internal and/or external) environmental variables can both influence the expression of pain, psychopathology, and substance abuse, and may therefore be useful in identifying or predicting controlled substance abuse (9). Such variables include pain resulting from traumatic accidents, involvement of multiple painful sites, and past history of illicit drug use (10). Ives et al (66) identified past cocaine abuse, drug or DUI conviction, and past alcohol abuse as predictors of misuse. Other studies (68-70) showed higher use of certain illicit drugs in patients that misuse or abuse opiates (32\% versus $14 \%)$. That socio-economic and chronicity-factors may play a role (or be part of this constellation of covariant features) was suggested by Manchikanti et al $(71,72)$ who showed increased levels of both (controlled) prescription drug misuse and illicit drug use in Medicaid patients. Notably, such misuse was shown to be significantly reduced by adherence monitoring (11,71-73).

While these later findings are encouraging, it is critical to recognize that 1 ) there are a multitude of possible variables contributing to pathologic expression, 2) there are numerous screening instruments 
available that could be used to evaluate pain, psychopathology, substance misuse-abuse, and various environmental factors, but 3) to date we do not yet have an ideal instrument that effectively meets these contingencies, or sufficiently identifies correlative indices that can validly and reliably predict the potential for substance misuse/abuse. There are number of potential limitations with each and all of these instruments. Not least of which is that some focus upon the acquisition of objective patient-related data, while others attempt to gain insight to more subjective domains of patient experience. In either or both of these approaches, some information may be misrepresented, missed, or lost. It may be that patients simply cannot understand what is being asked of them, and as a result, the information provided will be inaccurate. For example, Wallace et al (74) evaluated the complexity and legibility of self-administered opioid assessment screening tools for use in adults with non-malignant pain, and concluded that formatting characteristics (including semantic problems and ease of comprehension of several opioid assessment screening tools) may hinder many patients' ability to accurately and independently complete these instruments

Thus, it is recommended that multiple instruments and a cohesive and coordinated approach be used to identify and assist prediction of drug misuse and abuse in patients receiving opiates for chronic pain. An assessment approach utilized by the first author is listed in Table 4. However, while this has proven to be effective and useful, it may not provide total validation and appropriate results in all patients,

Table 4. Commonly used criteria for evaluation of drug abuse.

\begin{tabular}{|c|c|c|}
\hline \multicolumn{3}{|l|}{ i. DRUG ABUSE } \\
\hline \multicolumn{3}{|l|}{ 1. Excessive opiate needs } \\
\hline i. Multiple dose escalations & $\square$ No & $\square$ Yes \\
\hline ii. Multiple emergency room visits & $\square$ No & $\square$ Yes \\
\hline iii. Multiple calls to obtain more opiates & $\square$ No & $\square$ Yes \\
\hline iv. Repeatedly asking for higher doses & $\square$ No & $\square$ Yes \\
\hline v. Taking opiates or other controlled substances from others & $\square$ No & $\square$ Yes \\
\hline 2. Deception or lying to obtain controlled substances & $\square$ No & $\square$ Yes \\
\hline 3. Current or prior intentional doctor shopping & $\square$ No & $\square$ Yes \\
\hline 4. Current or prior use of illicit drugs and denial & $\square$ No & $\square$ Yes \\
\hline \multicolumn{3}{|l|}{ Diagnosis: __ Negative __Positive ( 2 or more) } \\
\hline \multicolumn{3}{|l|}{ ii. SUBSTANCE ABUSE } \\
\hline \multirow{2}{*}{\multicolumn{3}{|c|}{$\begin{array}{l}\text { Maladaptive pattern leading to distress or impairment } \\
\text { Recurrent failure to fill role }\end{array}$}} \\
\hline & $\square$ No & $\square$ Yes \\
\hline \multicolumn{3}{|l|}{ Recurrent physically hazardous behavior } \\
\hline Recurrent legal problems & $\square$ No & $\square$ Yes \\
\hline \multicolumn{3}{|l|}{ Continued use despite social problems } \\
\hline \multicolumn{3}{|l|}{ Met dependence criteria } \\
\hline \multirow{2}{*}{\multicolumn{3}{|c|}{$\begin{array}{l}\text { Diagnosis: __ Negative __ Positive (at least once in } 12 \text { months) } \\
\text { iii. SUBSTANCE DEPENDENCE }\end{array}$}} \\
\hline & & \\
\hline Tolerance & $\square$ No & $\square$ Yes \\
\hline Withdrawal & $\square$ No & $\square$ Yes \\
\hline \multicolumn{3}{|l|}{ Larger amounts / longer periods } \\
\hline \multirow{2}{*}{\multicolumn{3}{|c|}{$\begin{array}{l}\text { Efforts or desire to cut down } \\
\text { Large amount of time using / obtaining / recovering }\end{array}$}} \\
\hline & $\square$ No & $\square$ Yes \\
\hline Activities given up: social / work / recreation & $\square$ No & $\square$ Yes \\
\hline \multicolumn{3}{|l|}{ Continued use despite problems } \\
\hline \multicolumn{3}{|l|}{$\begin{array}{l}\text { Diagnosis: } \_ \text {Negative __Positive (at least three in } 12 \text { months) } \\
\text { iv. ADDICTION }\end{array}$} \\
\hline \multicolumn{3}{|l|}{ Loss of control } \\
\hline \multicolumn{3}{|l|}{ Craving } \\
\hline \multicolumn{3}{|l|}{ Compulsive use } \\
\hline \multicolumn{3}{|l|}{ Continued use despite consequences } \\
\hline Diagnosis: __ Negative __Positive (all) & & \\
\hline
\end{tabular}


and/or for each and all clinical settings. However we offer this approach both as a template and to illustrate how the criteria (and specificity) of various assessment instruments may be combined to afford maximum effectiveness and utility. Table 5 illustrates these common criteria as cited in the literature. In theory, perhaps the best approach would be one that combines the use of instruments that allow (objective and subjective) assessment of particular cognitions, emotions, and behaviors, with evaluation of biomarkers that have been shown to be valid indicators of genotypic predisposition and/or expression of particular (pathologic) phenotypes. While there has been some progress in developing such biomarker analyses, to date, specific identification of genetic or phenotypic markers that have high predictive value for substance abuse remains tentative.

\section{Urine Drug Testing}

Currently, the use of biological sample screening to depict drug levels enjoys utility as a method 1) to detect the presence of opioids and other drugs prior to, and/or at the beginning of, treatment that may be indicative of (patterns/extent of) previous and current drug use; 2 ) to establish relative baselines from which treatment compliance may be evaluated, and/or 3) to suggest/indicate illicit drug use.

One of the most simple, non-invasive approaches to biological sample screening is urine analysis. While drug testing may be performed by either testing the urine, serum, or hair, urine drug testing is regarded as the gold standard. This is primarily because urinary assay allows for the presence or absence of certain drugs to be evaluated with (relatively) good specificity, sensitivity, ease of administration, and cost. However, controversies exist regarding the clinical value

Table 5. Summary description of key criteria in the literature.

\begin{tabular}{|c|c|c|c|c|}
\hline $\begin{array}{l}\text { Criteria by Atluri and } \\
\text { Sudarshan (47) }\end{array}$ & Criteria by Chabal et al (36) & $\begin{array}{l}\text { Criteria by Compton } \\
\text { et al (48) }\end{array}$ & $\begin{array}{l}\text { Criteria by } \\
\text { Manchikanti et al } \\
\text { (54) }\end{array}$ & $\begin{array}{l}\text { Criteria by Savage } \\
\text { (26) }\end{array}$ \\
\hline Focused on opioids & $\begin{array}{l}\text { Overwhelming focus on opiate issues } \\
\text { during pain clinic visits, persistent } \\
\text { beyond the third clinic treatment } \\
\text { session }\end{array}$ & $\begin{array}{l}\text { Belief of addiction by } \\
\text { the patient }\end{array}$ & Excessive opiates needs & $\begin{array}{l}\text { Unwillingness to } \\
\text { taper opioids }\end{array}$ \\
\hline Opioid overuse & $\begin{array}{l}\text { The pattern of early refills ( } 3 \text { or } \\
\text { more) or escalating drug use in the } \\
\text { absence of an acute change in the } \\
\text { medical condition }\end{array}$ & $\begin{array}{l}\text { Increasing analgesic } \\
\text { dose or frequency }\end{array}$ & $\begin{array}{l}\text { Deception or lying } \\
\text { to obtain controlled } \\
\text { substance }\end{array}$ & $\begin{array}{l}\text { Effective analgesia, } \\
\text { but decreased } \\
\text { function }\end{array}$ \\
\hline Other substance use & $\begin{array}{l}\text { Multiple telephone calls or visits } \\
\text { with requests for more opiates, early } \\
\text { refills, or problems associated with } \\
\text { the opiate prescription }\end{array}$ & $\begin{array}{l}\text { Route of } \\
\text { administration } \\
\text { preference }\end{array}$ & Doctor shopping & Early refills \\
\hline Non-functional & $\begin{array}{l}\text { Prescription problems, including lost } \\
\text { medications, spilled medications, or } \\
\text { stolen medications }\end{array}$ & & & \\
\hline Exaggeration of pain & $\begin{array}{l}\text { Opiates obtained from multiple } \\
\text { providers, emergency rooms, or } \\
\text { illegal sources }\end{array}$ & & & \\
\hline Etiology of pain unclear & & & & \\
\hline
\end{tabular}


of urine drug testing, partly because most current methods are designed for, or adapted from, forensic or occupational deterrent-based testing for illicit drug use and are not entirely optimal for applications in the chronic pain management setting. Yet, with appropriate consideration of the caveats against misinterpretation (arising from limits of specificity, and/or falsepositive or false-negative screens), urine drug testing can be a useful tool to aid in both the ability to evaluate patients' compliance with prescribed regimens of controlled substances and to diagnose the misuse or abuse of prescribed drugs or use of illicit agents.

The term "urine drug screening" is actually a misnomer since it implies a generic screening for any and all drugs; it is impossible to prove the presence or absence of all drugs. There is not a standard "urine drug test" that is suitable for all purposes and settings. However, there are numerous types of urine analyses that physicians can employ to meet their clinical needs (75-77).

Urine drug testing is a useful tool in managing chronic pain patients that are treated with controlled substances. As matter of fact, urine drug testing is becoming a somewhat routine practice in chronic pain management settings. Urine drug testing is most commonly used for 2 purposes. First, is to detect the presence of prescribed medications (i.e., compliance testing) and second is to identify substances that are not expected to be present in the urine (e.g., non-prescription and illicit drugs, i.e., forensic testing).

Compliance testing is extremely useful as the physician is looking for the presence of prescribed medications as evidence of their appropriate use while positive results indicate appropriate use and also compliance with the treatment plan, absence of prescribed drugs or finding unprescribed or illicit drugs are concerning and mandate further evaluation and management.

\section{Urine Drug Testing Methods}

There are typically 2 types of urine drug testing. These include immunoassay drug testing (either laboratory-based or office-based, the latter being colloquially referred to as "dipstick testing") and laboratory-based specific drug identification utilizing gas chromatographic/mass spectroscopy (GC/MS), high performance liquid chromatography (HPLC). The combination of these testing methods can ensure accuracy and improve efficacy, yet using both may be costly. The method used is dependent on the reason(s) for, and desired sensitivity of the test. Immunoassay drug tests are designed to determine the presence or ab- sence of particular substances according to a predetermined threshold, and are the most common methods utilized. However, identification of a specific drug may be needed, and this mandates the use of GC/MS.

\section{Methodological Issues in Urine Drug Testing}

Immunoassays are based on the principle of competitive binding, and use antibodies to detect the presence of a particular drug or metabolite in a urine sample. Immunoassay drug testing is provided either in the laboratory or by means of rapid drug testing at the point of service. The capability of a particular immunoassay to detect drugs can vary according to both the drug concentration in the urine and the assay's cut-off concentration. Any indication of a drug above the cut-off is deemed to be positive, and any response below the cut-off is negative. However, almost all, immunoassays are subject to cross-reactivity. For example, while tests for cocaine are highly predictive of cocaine use, tests for amphetamine/methamphetamine are highly cross-reactive, and may detect other sympathomimetic amines (e.g., ephedrine and pseudoephedrine) and therefore are frequently unreliable and may lack predictive or diagnostic value. Standard tests for opiates are very responsive for morphine and codeine, but cannot distinguish which specific substance is present. As well, these assays show a lower sensitivity for semisynthetic/synthetic opioids (e.g., oxycodone, fentanyl, methadone, and buprenorphine), and therefore a negative response does not exclude use of these opioids. At this writing, specific immunoassay tests for semi-synthetic/synthetic opioids are not commercially available.

In contrast to immunoassays or rapid drug testing, laboratory-based specific drug identification is both more sophisticated and more expensive. Laboratory-based specific drug identification is needed to confirm the presence of a given drug, and/or to identify drugs not isolable by screening test(s). Table 6 illustrates cut-off levels for various drugs detected by urine analysis. In chronic pain management settings, a panel for rapid drug screening should ideally include opioids (including oxycodone and methadone) as well as benzodiazepines, barbiturates, marijuana, cocaine, amphetamines, and methamphetamines. If a custom panel is not available, multiple tests may be required as rapid drug screening(s). Note that detection times can vary considerably, depending upon acute versus chronic use, the particular drug used within a class, individual characteristics of the patient, and the method used to test for a substance. Since both false-nega- 
Table 6. Urine drug testing: Typical screening and confirmation cut-off concentrations and detection times for drugs of abuse.

\begin{tabular}{|c|c|c|c|c|c|}
\hline Drug & $\begin{array}{l}\text { Screening } \\
\text { cut-off } \\
\text { concentrations } \\
\text { ng/mL urine }\end{array}$ & $\begin{array}{l}\text { Analyte tested in } \\
\text { confirmation }\end{array}$ & $\begin{array}{l}\text { Confirmation cut- } \\
\text { off concentrations } \\
\text { ng/mL } \\
\text { (non-regulated) }\end{array}$ & $\begin{array}{l}\text { Confirmation cut- } \\
\text { off concentrations } \\
\text { ng/mL } \\
\text { (federally regulated) }\end{array}$ & $\begin{array}{l}\text { Urine detection } \\
\text { time }\end{array}$ \\
\hline Amphetamine & 1,000 & Amphetamine & 500 & 1,000 & 2-4 days \\
\hline Barbiturates & 200 & $\begin{array}{l}\text { Amobarbital, } \\
\text { secobarbital, other } \\
\text { barbiturates }\end{array}$ & 200 & 300 & $\begin{array}{l}\text { 2-4 days for short } \\
\text { acting; up to } 30 \text { days } \\
\text { for long acting }\end{array}$ \\
\hline Benzodiazepines & 200 & $\begin{array}{l}\text { Oxazepam, diazepam, } \\
\text { other benzodiazepines }\end{array}$ & 200 & 300 & Up to 30 days \\
\hline Cocaine & 300 & Benzoylecgonine & 150 & 300 & 1-3 days \\
\hline Codeine & 300 & Codeine, morphine & $300 ; 300$ & 2,$000 ; 300$ & 1-3 days \\
\hline Heroin & 300 & $\begin{array}{l}\text { Morphine, } \\
\text { 6-acetylmorphine }\end{array}$ & $300 ; 10$ & 2,$000 ; 300$ & 1-3 days \\
\hline Marijuana & $100 ; 50 ; 20$ & Tetrahydrocannabinol & 15 & 50 & $\begin{array}{l}\text { 1-3 days for casual } \\
\text { use; up to } 30 \text { days } \\
\text { for chronic use }\end{array}$ \\
\hline Methadone & 300 & Methadone & 300 & 300 & 2-4 days \\
\hline Methamphetamine & 1,000 & $\begin{array}{l}\text { Methamphetamine, } \\
\text { amphetamine }\end{array}$ & $500 ; 200$ & 1,$000 ; 50$ & 2-4 days \\
\hline Phencyclidine & 25 & Phencyclidine & 25 & 25 & $\begin{array}{l}2-7 \text { days for casual } \\
\text { use; up to } 30 \text { days } \\
\text { for chronic use }\end{array}$ \\
\hline
\end{tabular}

tives and false-positives are possible, questionable results should always be followed by confirmatory or no-threshold laboratory testing prior to taking any action(s) (such as confronting the patient, altering treatment plans, etc.).

\section{Federally Regulated Testing}

Federally regulated testing is the most established use of urine drug testing - assaying 5 drugs in federal employees and federally regulated industries; marijuana, cocaine, opiates, PCP, and amphetamines/methamphetamines (78). Positive results based on immunoassays alone are referred to as presumptive positives, because of the possibility for cross-reactivity, differing sensitivity, and variable specificity in given immunoassays (76). Consequently, results of federally regulated testing must be confirmed by a more specific method such as gas chromatography/mass spectometry (GC/ MS). Federally regulated testing methods are generally not applicable in most clinical pain management settings in light of the street sample and chain of custody requirements that are mandated in all federal testing. As well, the cut-off concentrations used in federally regulated testing (particularly the reference cut-off concentrations utilized for opioids) are too high to be of value in clinical practice.

\section{Non-Regulated Testing}

In contrast, non-regulated testing methods are more generally used in the clinical setting and can be customized to meet the specific needs incurred in individual practices (77). Non-regulated testing may be performed for legal purposes, including child custody cases, drivers' license revocation, criminal justice, insurance purposes, workers compensation, sports testing, and pre-employment screening or random workplace testing (79). In such instances these tests may require a chain of custody, provision of split samples, and secure storage of non-negative samples. Recently, urine drug testing has become more commonly used to screen middle and high school children participating in competitive sport activities (80). The scope of testing in these settings exceeds the federal 5 drugs and several other drugs are routinely assayed including methadone, propoxyphene, benzodiazepines, oxycodone, and barbiturates. 


\section{Practical Aspects}

In clinical settings, urine drug testing is utilized for compliance, as well as forensic testing to monitor therapeutic activity, misuse, and illegal drug use. Consequently, the initial and confirmatory testing levels, as well as the number of drugs tested, can be customized and are usually different from those evaluated under federal testing programs. Table 6 illustrates typical detection times for urine drug testing of common drugs of abuse, cut-off levels, and comparison of federally regulated cut-off and concentration levels. As illustrated in the table, opioid cutoff levels in clinical settings are $300 \mathrm{ng}$ per $\mathrm{mL}$, which allows for a considerably more sensitive assay than the 2,000 ng per $\mathrm{mL}$ that is employed in federal cut-off levels.

\section{Caveats in Urine Drug Testing}

Drug screening can be an important tool to ensure patient compliance with prescription regimens. Drug screening or testing may be effectively performed in the physician's office using point of contact (POC) urine (dipstick) immunoassay testing. However, practitioners using POC testing need to be aware of whether the system used is compliant with methods and assurances established by the Clinical Laboratory Investigative Association (CLIA). A CLIA waiver is required to perform certain tests (including urine immunoassay). Only immunoassay tests for certain drugs are CLIA waived, and these may be performed in the office only if (and when) a certificate of waiver is first obtained by the physician. Generally these tests do not require extensive training for office personnel. Unfortunately however, Medicare and other payors do not uniformly allow all CLIA-waived testing, and it becomes incumbent upon physicians to determine which tests will be covered by patients' insurance programs.

When considering the effectiveness, validity, and/or viability of differing types of drug screens, gas chromatography/mass spectrographic (GC/MS) confirmation by an independent laboratory is most commonly regarded as the best (i.e., most sensitive) drug screen. GC/MS measurements allow high quality, precise measures of a variety of drugs that are relevant to chronic pain management. GC/MS should be considered a confirmatory test in those circumstances in which the initial urine drug screen findings would prompt a change in therapy. POC immunoassay tests are generally shown to be greater than $95 \%$ accurate if performed and interpreted correctly, but it is important that physicians understand the limitations of POC immunoassay so as to direct when and why GC/MS evaluation can and should be used. Table 7 presents potential sources of drug screen cross reactivity. Toxicologists from laboratories performing GC/MS testing are readily available to discuss interpretation(s) of the results. It is equally important that physicians establish a solid working relationship with a reliable testing company to ensure that any/ all inquiries relevant to screen interpretation and confirmation(s) can be addressed.

Additionally, the importance of understanding the validity of the sample cannot be understated.

Table 7. Drug cross-reactants.

\begin{tabular}{|l|l|}
\hline \multicolumn{2}{|l|}{ Drug Cross-Reactants } \\
\hline Drug & Cross-Reactant \\
\hline Cannabinoids & NSAIDs, Marinol, Protonix \\
\hline Opioids & Poppy seeds, chlorpromazine, rifampin, dextromethorphan quinine \\
\hline Amphetamines & $\begin{array}{l}\text { Ephedrine, methylphenidate, trazodone, bupropion, desipramine, Amantadine, ranitidine, phenylpropanolamine, } \\
\text { Vicks Vapor Spray }\end{array}$ \\
\hline PCP & Chlorpromazine, thioridazine, meperidine, dextromethorphan, diphenhydramine, doxylamine \\
\hline Benzodiazepine & Oxaprozin (Daypro ${ }^{\circ}$, some herbal agents \\
\hline ETOH & Asthma inhalers (sometimes) \\
\hline Methadone & propoxyphene, Seroquel \\
\hline
\end{tabular}

Gas chromatography should confirm all positives and screen detects a presence of absence, not the concentration. Drug tests are not quantitative. 
Urine can be adulterated; there are many commercially available urine samples or adulterants that can alter the validity of urine that is to be submitted (to physicians and laboratories for testing. Fortunately, the vast majority of these reagents are unreliable or easily detected by common testing methods. Common techniques, such as commercially available "clean" urine samples, and/or getting specimens from another individual are situations that physicians need to recognize: If collected within 4 minutes, the temperature range of urine should be between $90^{\circ}$ and $100^{\circ} \mathrm{F}$; the $\mathrm{pH}$ should be between 4.5 and 8 , and the creatinine norm is $20 \mathrm{mg} / \mathrm{dl}$ or greater. Dilute urine has $<20 \mathrm{mg} /$ $\mathrm{dl}$ creatinine, while alien urine is $<5 \mathrm{mg} / \mathrm{dl}$. Significant variation from these standards should be regarded with some suspicion, and may suggest the need for reasonably prompt re-sampling.

Interpretation of drug screens must include knowledge of opioid metabolites. For example, a urine screen that is positive for hydromorphone in a patient receiving hydrocodone does not reflect drug abuse, but rather the appropriate metabolism of hydrocodone. Similarly, since codeine is metabolized to morphine, a screen that is positive for morphine in a patient taking codeine would be expected. Historically, there have been instances in which physicians who were not familiar with opioid metabolism have wrongly accused patients of drug abuse (Tables 8 and 9); we maintain that given the pain physicians' professional role and responsibilities (for expert knowledge, and competence in practice), such errors are inexcusable. Physicians should establish a conservative, but

Table 8. Metabolism of codeine, heroin, morphine, and hydrocodone.
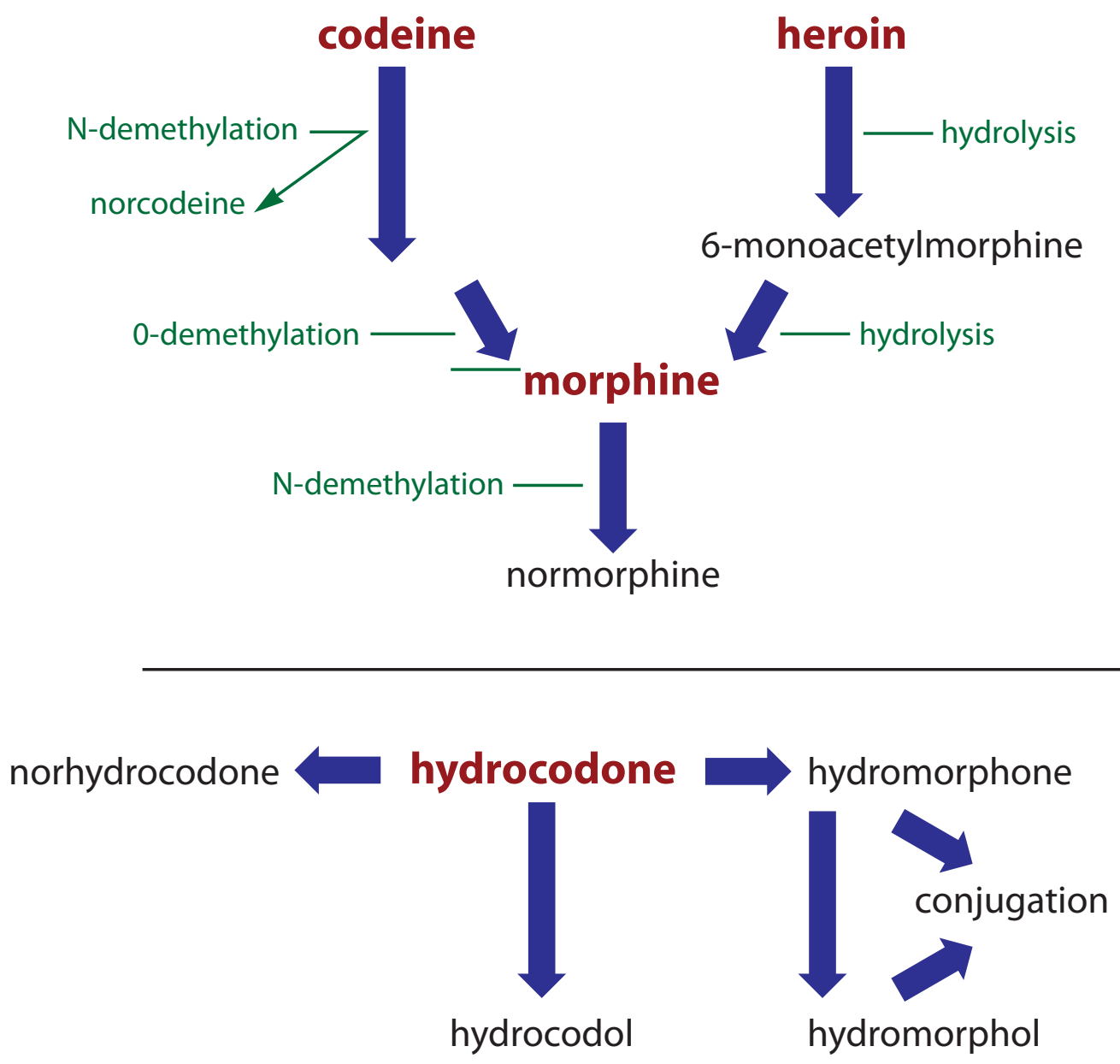
Table 9. Metabolites of opioids.

\begin{tabular}{|l|l||}
\hline Opiate & Metabolites \\
\hline Morphine & $\begin{array}{l}\text { M3G and M6G } \\
\text { Normorphine }\end{array}$ \\
\hline Meperidine & Normeperidine \\
\hline Levorphanol Tartrate (Levo-Dromoran) & Long half-life \\
\hline Hydromorphone & Hydromorphone-3-glucuronide (H3G) \\
\hline Oxycodone & $\begin{array}{l}\text { Noroxycodone, oxymorphone, oxycodols, and their respective oxide } \\
\text { Codeine }\end{array}$ \\
\hline Hydrocodone & $\begin{array}{l}\text { Norcodeine } \\
\text { Morphine }\end{array}$ \\
\hline Propoxyphene & $\begin{array}{l}\text { Normorphine } \\
\text { Norhydrocodone } \\
\text { Hydrocodol } \\
\text { Hydromorphone } \\
\text { Hydromorphol }\end{array}$ \\
\hline
\end{tabular}

Table 10. Performance characteristics of different types of assays for drugs of abuse.

\begin{tabular}{|l|c|c|c|c|c||}
\hline \hline Assay & Sensitivity & Specificity & Accuracy & Turnaround time & Cost \\
\hline Onsite & Moderate-high & Moderate & Qualitative & Minutes & $\$ 4-25$ \\
\hline $\begin{array}{l}\text { EMIT, } \\
\text { FPIA, } \\
\text { RIA, } \\
\text { KIMS }\end{array}$ & Moderate-high & Moderate & Low-high & $1-4$ hours & $\$ 1-5$ \\
\hline TLC & & & & $1-4$ hours & $\$ 1-4$ \\
\hline GC & Low-high & High & Qualitative* & Days & $\$ 5-20$ \\
\hline GC/MS & High & High & High & Days & $\$ 10-100$ \\
\hline
\end{tabular}

KEY: $E M I T=$ enzyme-multiplied immunoassay technique; FPIA = fluorescent polarization immunoassay; RIA = radioimmunoassay; KIMS = kinetic interaction of microparticles in solution; $\mathrm{TLC}=$ thin layer chromatography; $\mathrm{GC}=$ gas chromatography; $\mathrm{GC} / \mathrm{MS}=\mathrm{GC} /$ mass spectrometry. * $=$ Results for onsite tests and TLC assays are generally expressed only in qualitative terms (i.e., positive/negative); consequently, accuracy may be difficult to assess.

Source: Cone EJ (81) 
firm policy regarding the response to a positive drug screen. First and foremost, the accuracy of the screen should be verified, and any potential sources of error identified as illustrated in Table 10 (81). A repeat screen may be required, and we advocate that when in doubt, it is advisable to repeat the screen as quickly as possible.

Table 11 illustrates drug testing for cocaine, its specificity, pitfalls, and myths, whereas, Table 12 illustrates urine drug testing for marijuana, which is mod- erately specific, while Table 13 illustrates drug testing for amphetamines with low specificity. Further, Table 14 illustrates pitfalls of opioid drug testing, along with cross-reactivity. Upon confirmation of a true-positive screen, referral to an addictionologist or psychologist, and/or addressing, proposing, and prudently implementing a change in treatment plan (e.g., refusal to prescribe opioids in favor or other non-opioid analgesics) may be warranted. However, we emphasize that a positive drug screen usually does not warrant dis-

Table 11. Urine drug testing methods for cocaine testing — very specific.

- Tests for cocaine react principally with cocaine and its primary metabolite, benzoylecgonine.

- These tests have low cross-reactivity with other substances

- Very specific in predicting cocaine use.

- Cocaine, a topical anesthetic, is clinically used in certain trauma, dental, ophthalmoscopic, and otolaryngologic procedures.

- A patient's urine may test positive for up to 2 to 3 days.

- There is no structural similarity between other "caines" and cocaine or benzoylecgonine.

- Cross-reaction does not occur.

A positive UDT result for the cocaine metabolite, in the absence of a medical explanation, should be interpreted as due to deliberate use.

Cocaine Myths
Coca Tea

- There have been rare, but documented cases of cocaine ingestion by drinking tea made from coca leaves.

- The product-containing cocaine and/or related metabolites-is illegal under the U.S. Drug Enforcement Administration and Food and Drug Administration regulations.

- Patients should be advised not to use coca tea.
Table 12. Urine drug testing for marijuana.

\begin{tabular}{|l}
\hline THC: Marijuana: Moderate Specificity \\
Reasonable reliability \\
Positive result \\
False-positive result \\
- $\quad$ Protonix \\
Marijuana Myths \\
Passive Inhalation \\
- In extreme conditions (e.g., it is possible to blow enough \\
$\quad$ smoke in an individual's face to cause them to become \\
positive for marijuana). \\
Medical Marijuana \\
- Marinol for the control of nausea, vomiting, and appetite \\
stimulating. \\
More specific testing would be required to distinguish \\
between natural and synthetic THC.
\end{tabular}

Table 13. Drug testing for amphetamines.

Low Specificity

- Tests for amphetamine/methamphetamine are highly crossreactive.

- They will detect other sympathomimetic amines such as ephedrine and pseudoephedrine.

- Not very predictive for amphetamine/methamphetamine use.

- Further testing is required.

- Positive results can be challenging due to structural similarities of:

- $\quad$ Many prescription and OTC products, including diet agents, decongestants, and certain drugs used in the treatment of Parkinson's disease.

- Knowledge of potential sources of amphetamine and methamphetamine can prevent misinterpretation of results. 
Table 14. Pitfalls of opioid drug testing.

\section{Pitfalls}

- Tests for opiates are very responsive for morphine and Codeine.

- Do not distinguish which is present.

- Show a low sensitivity for semisynthetic/synthetic opioids such as oxycodone.

- A negative response does not exclude oxycodone, methadone use.

- Opiate immunoassays designed to detect morphine and codeine do not reliably detect synthetic or semisynthetic opioids.

- Cross-reacting compounds can also be structurally unrelated to the standardizing compound.

- Several quinolone antibiotics (eg, levofloxacin, ofloxacin) can potentially cause false-positive results for opiates by common immunoassays, despite no obvious structural similarity with morphine.

- Quinolones are not misinterpreted as opiates by GC/MS.

Cross-reactivity

- Detection of a particular drug by a drug-class specific immunoassay depends on:

- The structural similarity of that drug or its metabolites to the compound used for standardization

- The urine concentration of that drug/metabolite, compared with the standardizing compound .

- The ability of opiate immunoassays to detect synthetic or semisynthetic opioids, such as methadone or oxycodone, varies among assays due to differing cross-reactivity patterns.

- Methadone, although an opioid, does not trigger a positive opioid immunoassay result unless a specific methadone test is used.

- In the case of oxycodone, even large concentrations in the urine may not reliably be detected.

missal of the patient. Along these lines, we advocate that a similar policy regarding the inappropriate use of drugs prescribed by the physician (as well as "doctor shopping" for multiple prescriptions) should also be systematically and consistently employed.

\section{Prescription Drug Monitoring Programs}

Several states began to address the misuse and abuse of medications in the 1940s by creating programs to monitor the dispensing of prescription drugs (4). Initially, these programs only monitored Schedule II drugs by requiring physicians to use special multi- ple-copy, 2- or 3-part prescription order forms, with a copy sent to a state monitoring program. By 1999, 15 states had adopted prescription drug monitoring programs, but these programs were quite diverse. Some programs were able to initiate electronic reporting, but most still used a variety of triggers (such as number of prescriptions written or volume of medications prescribed) to "flag" physicians or patients for further investigation. Kentucky established the Kentucky All Schedule Prescription Electronic Reporting program (KASPER); while this was an effective program of drug monitoring, it was limited by the fact that the 7 border states that surround Kentucky allowed patients to refill prescriptions across state lines in order to circumvent the program.

In 2002, Congress began appropriate funding to the U.S. Department of Justice (DOJ) to support the Harold Rogers Prescription Drug Monitoring Program (U.S. Department of Justice Appropriations Act). The purpose of the program was to enhance the capacity of regulatory and law enforcement agencies to collect and analyze controlled substance prescription data. However, because it was administered through DOJ, the emphasis was on enforcement, not prevention. President Bush signed the National All Schedules Prescription Electronic Reporting (NASPER) Act on August 11, 2005, making it the only statutorily authorized program to assist states in combating abuse of controlled substances through a prescription drug monitoring program (PDMP), and authorizing the U.S. Department of Health and Human Services (HHS) to award grants to states to construct prescription drug monitoring programs and enhance communication between those programs in existence. Unfortunately, funding has not yet been provided for this activity (4).

In practice, PDMPs take different forms because each state government determines the goals, structure, and organization of its respective program. As of December 2006, 33 states have signed laws authorizing the creation of PDMPs; 25 have active programs, while 8 have begun implementation. The manner in which a program is implemented depends upon the stated goals and mission of the responsible agency (82). Most state PDMPs have the following goals (83):

- To educate and inform practitioners and the public,

- To develop and advance public health initiatives, 
- To facilitate early identification and intervention in cases of drug misuse or abuse,

- To aid investigation and law enforcement, and

- To safeguard the integrity and access to the programs' database.

A recent report sponsored by DOJ Office of Justice Programs examined the relationship between the presence of a PDMP and the availability and abuse of prescription drugs (84). The report compared trends in abuse of prescription pain relievers and stimulants between states that have a CSMP and those that do not (Table 15). The principal findings suggested that the presence of a PDMP may reduce the per capita supply of prescription pain medications and thereby reduce the probability of abuse, and that proactive programs appear to be more effective than reactive programs in achieving these outcomes. Unfortunately, many state programs only report Schedule II drugs, and the DOJ report confirmed that other scheduled medications have a higher availability and are frequently abused more than Schedule II agents (84). Table 16 presents the parameters of current monitoring programs (85).

Because of the brief time frame (18 months since the passage of the NASPER Act) and the relative recency of significant upgrades in PDMPs (e.g., electronic data sharing), the effect (and effectiveness) of PDMPs remains difficult to ascertain. However, a notable observation was that programs monitoring Schedule II drugs may initiate or provoke a shift to Schedule III prescribing.

We believe that these findings need to be approached with some caution for 2 reasons. First, as discussed by Brushwood (87), the true measure of PDMP impact would be in the difference between

Table 15. Average number of purchases per person of Schedule II drugs in CSMP and non-CSMP states, 1996-2003.

\begin{tabular}{|c|c|c|c|c|c|c|}
\hline \multicolumn{7}{|c|}{ Percent of Population with Any Prescriptions ${ }^{1}$} \\
\hline & \multicolumn{2}{|c|}{ All Years 1996-2003 } & \multicolumn{2}{|c|}{1996} & \multicolumn{2}{|c|}{2003} \\
\hline State CSMP Category & With CSMP1 & No CSMP & With CSMP & No CSMP & With CSMP & No CSMP \\
\hline \multicolumn{7}{|l|}{ Type of Drug } \\
\hline All Schedule II Drugs & 1.97 & $3.94^{*}$ & 1.42 & $3.14^{*}$ & 2.66 & $4.63^{*}$ \\
\hline \multicolumn{7}{|l|}{ Schedule II: } \\
\hline Opioid Analgesic & 1.16 & $2.90^{*}$ & 0.81 & $2.24^{*}$ & 1.64 & $3.52^{*}$ \\
\hline Stimulant & 0.82 & $1.08^{*}$ & 0.62 & 0.93 & 1.02 & 1.17 \\
\hline \multicolumn{7}{|l|}{ Non-schedule II: } \\
\hline Opioid Analgesic & 7.56 & 7.46 & 8.05 & 8.07 & 7.93 & 8.12 \\
\hline \multicolumn{7}{|c|}{ Number of Prescriptions Per 100 Persons $^{2}$} \\
\hline & \multicolumn{2}{|c|}{ All Years 1996-2003 } & \multicolumn{2}{|c|}{1996} & \multicolumn{2}{|c|}{2003} \\
\hline State CSMP Category & With CSMP & No CSMP & With CSMP & No CSMP & With CSMP & No CSMP \\
\hline \multicolumn{7}{|l|}{ Type of Drug } \\
\hline All Schedule II Drugs & 9.4 & $16.2^{*}$ & 6.2 & $10.1^{*}$ & 13.5 & $20.3^{*}$ \\
\hline \multicolumn{7}{|l|}{ Schedule II: } \\
\hline Opioid Analgesic & 4.7 & $9.0^{*}$ & 2.2 & $4.5^{*}$ & 6.9 & $11.9^{*}$ \\
\hline Stimulant & 4.7 & $7.2^{*}$ & 3.9 & 5.6 & 6.6 & 8.4 \\
\hline \multicolumn{7}{|l|}{ Non-schedule II: } \\
\hline Opioid Analgesic & 18.6 & 18.1 & 20.9 & 19.0 & 20.4 & 20.1 \\
\hline
\end{tabular}

1 "With CSMP" indicates that States implemented a program to monitor Schedule II drugs prior to 1996. "No CSMP" indicates that States had not implemented a program to monitor Schedule II drugs by 2003.

2 Use is estimated across all persons in the non-institutionalized U.S. population, regardless of whether they had any drug purchases during the year.

*The difference between the "With CSMP" and "No CSMP" estimate is significant at $p$

Source: Preliminary estimates are based on the 1996-2003 MEPS: Center for Financing, Access and Cost Trends, Agency for Healthcare Research and Quality (78).

NASPER Act of 2005 (89) 
Table 16. Prescription drug monitoring programs.

\begin{tabular}{|c|c|c|c|c|c|}
\hline State & $\begin{array}{l}\text { Year } \\
\text { started }\end{array}$ & $\begin{array}{l}\text { Schedules } \\
\text { monitored }\end{array}$ & $\begin{array}{l}\text { Administrative } \\
\text { agency }\end{array}$ & Access & $\begin{array}{l}\text { \# request } \\
\text { per month }\end{array}$ \\
\hline California & 1939 & II, III & $\begin{array}{l}\text { Pharmacy and law } \\
\text { enforcement }\end{array}$ & Prescribers $(70 \%)$ & 5,000 \\
\hline Hawaii & 1943 & II to IV & Law enforcement & $\begin{array}{l}\text { Law enforcement }(70 \%) \\
\text { Prescribers }(15 \%)\end{array}$ & 270 \\
\hline Idaho & 1967 & II to IV & Pharmacy board & Prescribers $(60 \%)$ & 1,100 \\
\hline Illinois & 1961 & II & Public health & $\begin{array}{l}\text { Law enforcement }(50 \%) \\
\text { Licensing board }(50 \%)\end{array}$ & 2 \\
\hline New York & 1977 & II to $\mathrm{V}$ & Public health & N/A & N/A \\
\hline Rhode Island & 1979 & II, III & Public health & N/A & N/A \\
\hline Texas & 1982 & II & Dept. Public Safety & $\begin{array}{l}\text { Prescribers }(40 \%) \\
\text { Licensing board (40\%) } \\
\text { Law enforcement }(20 \%) \\
\end{array}$ & 100 \\
\hline Washington & 1984 & $\begin{array}{l}\text { Determined } \\
\text { by disciplinary } \\
\text { authority }\end{array}$ & Dept. Health & N/A & N/A \\
\hline Michigan & 1988 & II to $\mathrm{V}$ & Board of Health & $\begin{array}{l}\text { Prescribers }(80 \%) \\
\text { Pharmacies }(15 \%)\end{array}$ & 5,000 \\
\hline Oklahoma & 1991 & II to $\mathrm{V}$ & Law enforcement & $\begin{array}{l}\text { Law enforcement (60\%), Licensing board } \\
(40 \%)\end{array}$ & 200 \\
\hline Massachusetts & 1992 & II & Public health & $\begin{array}{l}\text { Law enforcement }(61 \%) \\
\text { Licensing board }(30 \%)\end{array}$ & 10 \\
\hline Utah & 1995 & II to $\mathrm{V}$ & $\begin{array}{l}\text { Commerce's Licensing } \\
\text { Division }\end{array}$ & $\begin{array}{l}\text { Prescribers (40\%), Licensing board (40\%) } \\
\text { Law enforcement }(20 \%)\end{array}$ & 4,200 \\
\hline West Virginia & 1995 & II to IV & Board of Pharmacy & $\begin{array}{l}\text { Prescribers (65\%), Licensing board (2\%) } \\
\text { Law enforcement }(8 \%) \\
\text { Pharmacies }(25 \%)\end{array}$ & 1,000 \\
\hline Indiana & 1997 & II to V & Licensing board & Law enforcement $(100 \%)$ & 80 \\
\hline Nevada & 1997 & II to IV & $\begin{array}{l}\text { Pharmacy board and law } \\
\text { enforcement }\end{array}$ & $\begin{array}{l}\text { Prescribers }(85 \%) \\
\text { Pharmacy }(5 \%)\end{array}$ & 1,100 \\
\hline Kentucky & 1999 & II to $\mathrm{V}$ & Public health & Prescribers $(92 \%)$ & 2,300 \\
\hline Pennsylvania & 2002 & II & Office Attorney General & Law enforcement & 80 \\
\hline Maine & 2004 & II to IV & HHS & Prescribers $(83 \%)$ & 1,100 \\
\hline Wyoming & 2004 & II to IV & Board of Pharmacy & $\begin{array}{l}\text { Prescribers (85\%), Licensing board (3\%), } \\
\text { Law enforcement (2\%), Pharmacy (10\%) }\end{array}$ & 200 \\
\hline Mississippi & 2005 & II to $\mathrm{V}$ & Board of Pharmacy & $\begin{array}{l}\text { Licensing Board (50\%) } \\
\text { Law enforcement }(50 \%)\end{array}$ & 100 \\
\hline New Mexico & 2005 & II to IV & Board of Pharmacy & N/A & N/A \\
\hline Alabama & 2006 & II to $\mathrm{V}$ & DOJ, DEA & Licensing board & 80 \\
\hline Ohio & 2006 & II to $\mathrm{V}$ & Bureau of Pharmacy & N/A & N/A \\
\hline Tennessee & 2006 & II to $\mathrm{V}$ & Board of Pharmacy & N/A & N/A \\
\hline Virginia & 2006 & II to IV & Dept. Health Professions & $\begin{array}{l}\text { Prescribers (78\%), Licensing board (3\%) } \\
\text { Law enforcement (19\%) }\end{array}$ & 600 \\
\hline
\end{tabular}

Source: NASPER Act of 2005 (89) 
the amount of drug that is/was actually used and the amount that would have been used if a CSMP had not been in place, which, to date, is not known. Second, while ARCOS is an excellent indicator of drug distribution, it cannot track drug use. These distinctions are important because hospitals, clinics, and pharmacies order supplies of drugs (and the DEA sets quotas for drug manufacture and distribution) based upon past, but not current use. The Medical Expenditure Panel Survey (MEPS) may be a better monitoring window because it tracks actual drug use as dispensed to consumers. Data from MEPS showed an effect from PDMPs on opioid prescriptions: almost $3 \%$ of people in a nonPDMP state purchased at least one Schedule II analgesic, compared to $1.6 \%$ in states that had a PDMP (Tables 15 and 16). As previously mentioned, this suggests a type of "substitution effect" (switching from a higher-scheduled medication covered by a PDMP to a lower-scheduled drug that is not covered). Twillman (88) found that while the distribution of Schedule II opioids was lower, there was a higher distribution of Schedule III medications (especially hydrocodone combination products) in states that only monitored Schedule II medications, even compared to states that had no PDMP. We argue that this provides compelling evidence and reason that PDMPs should cover all scheduled medication(s).

There has been some concern that PDMPs could have a "chilling" effect on the appropriate prescribing of opioids. Such issues were examined in a survey of Virginia physicians conducted in mid-2004, and compiled by the Survey and Evaluation Research Laboratory of Virginia Commonwealth University. Physicians were asked if they had prescribed fewer Schedule II medications in the preceding 3 years after the initiation of a PDMP. Slightly more than a third of the respondents said that they had reduced prescribing of Schedule II drugs. Of this group, $48 \%$ cited intense media coverage of drug diversion as the reason, while $41 \%$ cited increased law enforcement activity. Almost a third (31\%) acknowledged that prescribing fewer Schedule II drugs had a negative effect on helping patients manage their pain (89).

Based upon a 2003 survey of 672 physicians in southwest Virginia, Barrett and Watson (90) noted physicians' lack of understanding of the goals and operations of PDMPs. Less than half of the responding physicians claimed that they were aware of the CSMP before receiving the survey. A total of $68 \%$ of the respondents reported that they expected the CSMP to be helpful in monitoring patients' prescription histories and reducing "doctor shopping," although only $11 \%$ had actually requested information from the prescription monitoring program database.

We assert that any healthcare policies, guidelines, and laws cannot be myopic, but must allow a clear vision of what and how present and potential future effects and consequences might be incurred. If the proximate goal of PDMPs (and guidelines and policies) is to reduce the potential for substance misuse or abuse, it cannot be forgotten that the ultimate goal is to improve the practice of medicine, not compromise its integrity. Legal policies that attempt to lessen patients' inappropriate use of opioids (and other agents) should not disenable sound pain care and/or incur physicians' inappropriate prescription of drugs as a defensive practice against litigation or professional sanction.

\section{Controlled Substance Agreements}

Given the contentious nature of controlled substance use in pain management, we opine that controlled substance agreements (CSA) may be invaluable tools to serve this purpose in that they can 1) clarify parameters of treatment, 2) explicate patient and physician responsibility, 3) inform patients of expectations and role(s), and 4) address potential consequences if these obligations and responsibilities are not upheld. In fact, CSAs are one of the most commonly used adherence monitoring tools in those medical practices in which opioids are used for the management of chronic pain. Manchikanti et al $(11,73)$ have shown a reduction in controlled prescription drug abuse and illicit drug use as a result of enhanced adherence monitoring utilizing a combination of screening tests, random drug testing, patient education, and CSAs. Fagan et al (91) surveyed internal medicine residents at a Rhode Island hospital regarding whether pain medication agreements (PMAs) were useful, and what percent of chronic pain patients taking opioids had signed a PMA. Ninety percent of respondents reported that PMAs were broadly useful, and it was noted that PMAs were (at least somewhat) helpful for 1) reducing multiple prescribers $(76 \%), 2$ ) reducing requests for early refills $(67 \%), 3)$ reducing calls and pages from patients requesting additional drugs $(57 \%), 4)$ discussing potential problems associated with chronic opioid use $(73 \%)$, and 5$)$ identifying patients who are abusing pain medications (66\%).

A CSA can serve as a binding, legal document be- 
tween the patient and physician or clinic. As such, it should describe potential issues that are essential to effective compliance with chronic opioid or controlled substance therapy, including risks and signs/symptoms of tolerance and physical and/or psychological dependence; misuse, abuse, illicit drug use, and the manifestations of these effects; and rules and regulations that deal with misuse, abuse, and illicit drug use, and the consequences of failing to adhere to the agreement. A CSA can often be of great benefit in explicating and clarifying the benefits, burdens, risks, and consequences of controlled substance use in pain management. It can serve as a "living document" — in other words, a source of discussion, and (some) progressive revision that allows both the valid provision of information (toward gaining consent to initiate and maintain treatment) and definition of physician and patient commitment and responsibilities.

\section{Approaching the "Drug Problem"}

Without question, there is a "drug problem"; but it is not a simple problem, and therefore cannot be mitigated by simple solutions. The nature of the problem is multi-fold: While it may be that opioids are inappropriately used and prescribed, it is important to identify the reasons for this misuse and mis-prescription. The temporal and financial dictates that have been imposed upon contemporary medical practice have led to a "turnstile" environment, in which both patients and physicians feel disempowered and dis-enfranchised from receiving and providing the "good" of clinical care, respectively. As a result, a prescription (e.g., for opioids) may be viewed as one of the few "tangibles" of the clinical encounter. That opioids are considered to be an agent of high(er) order on the analgesic ladder only tends to increase their relative "worth" or "value" to both patient and physician. As with anything of value, the "stakes" tend increase as a consequence of worth, meaning that both potential benefits and burdens are augmented.

The problem is not necessarily that opioid use will lead to the biological slippery slope of misuse, abuse, and addiction, but that the current market-model, and litigious climate of healthcare (in general, and pain medicine more specifically), can engage psychosocial slippery slope effects in which patients seek increasingly more "meaningful" relief for their pain. Given that patients frequently must wait a considerable amount of time for a medical appointment, and the clinical encounter itself may be relatively brief, pa- tients often view the "quid pro quo" as their libertarian "right" to the provision of some treatment that will maximize their subjective relief - and (opioid) drugs can easily be construed as the means to such relief. Given the "more is better" mentality of contemporary society, it is not unusual that some patients will escalate their frequency or amount of drug use. The issue is complicated by the possibility that geno- and phenotypic factors that sustain chronic pain (as well as pain reactivity and behaviors) may also affect sensitivity to opioids, and exacerbate over-, mis- and/or abuse of these drugs (9).

Obviously, pain physicians recognize the axiomatic obligation to safely and effectively treat patients' pain. Yet, given the subjective nature of pain, and the increasingly complex picture of pain as affected by (and correlated to) other neural and psychiatric conditions, including potential for substance abuse, the economic and temporal restrictions placed upon the practice of pain medicine may hamper physicians' abilities to spend sufficient time with each and every patient to allow insight into this complexity. Thus, physicians may feel compromised in their ability to exercise expert knowledge and capacity, and may be abreactive to patients explicit requests (if not demands) for specific (opioid) drugs in light of fears of malpractice litigation, DEA prosecution, or professional sanction.

The fiduciary of the clinical encounter is bilateral. Patients must trust that physicians know about pain, the risks and benefits of various treatment approaches, and are able to contextualize and use this information in patient-specific care. But, the physician must also trust the patient. Granted, the patients' obligations and responsibilities may be limited-reflecting the inequality of knowledge, capacity, and power in the clinical relationship-but at the very least, these responsibilities include commitment, veracity and respect.

In light of this, we believe that it is important for there to be some equivalent means to uphold and demonstrate patient conjoinment in, and obligation to, the medical relationship.

\section{Conclusion}

Long-term opioid therapy for chronic pain, while common, and frequently indicated and necessary, is associated with risks of adverse side effects as well as potential for misuse, abuse, illicit drug use, and diversion. It is incumbent upon the pain physician to be aware of those effects and to discuss the risks and 
benefits of the use of controlled substances with the patients or surrogate(s). As well, it is the physician's responsibility to recognize the potential for and occurrence of substance misuse, abuse, and addiction, and in light of this, the necessity of means of predictive assessment, determination, and treatment.

Adherence monitoring is essential in this regard, and mandates a prudent combination of initial evaluation(s) and periodic review and monitoring utilizing initial screening, testing, and evaluation throughout the course of treatment, using various screening tests, urine drug testing, prescription monitoring programs, and controlled substance agreements. Opioids have a defined place in the management of chronic pain. As with any therapeutic approach, the use of opioids is dependent upon numerous variables. These include whether the particular type of pain has been shown to be responsive to (some type and combination of) opioid(s); individual, patient-specific factors that are related to pre-dispo- sition to pain, opioid sensitivity, and abuse/addictive potential; the physicians' knowledge of these variables, comfort, and/or amenability to employ opioids in practice; and the ability to ensure that patients are sufficiently compliant so as to maximize the benefits and minimize the risks and burdens of treatment. Guidelines, policies, and laws must fortify such prudent practice, and it is important that any and all such policies and laws be protective (of the patients' best interests and the probity of medical practice), rather than being prohibitive or punitive.

\section{Acknowledgements}

The authors are grateful to Sherry Loveless, Holly Long, and transcriptionists, Tonie M. Hatton and Diane E. Neihoff, for their assistance in the preparation of this manuscript. This work was supported by a grant from the Laurance S. Rockefeller Trust, and funding from the Samueli Institute, and Division of Palliative Medicine and Center for Clinical Bioethics, Georgetown University Medical Center (JG).

\section{References}

1. Manchikanti L, Singh A. Therapeutic opioids: A ten year perspective on the complexities and complications of the escalating use, abuse, and non-medical use of opioids and other psychotherapeutics. Pain Physician 2008; 11:S63S88.

2. Manchikanti L. National drug control policy and prescription drug abuse: Facts and fallacies. Pain Physician 2007; 10:399-424.

3. Manchikanti L. Prescription drug abuse: What is being done to address this new drug epidemic? Testimony before the Subcommittee on Criminal Justice, Drug Policy and Human Resources. Pain Physician 2006; 9:287-321.

4. Manchikanti L, Whitfield E, Pallone F. Evolution of the National All Schedules Prescription Electronic Reporting Act (NASPER): A public law for balancing treatment of pain and drug abuse and diversion. Pain Physician 2005; 8:335347.

5. Trescot AM, Boswell MV, Atluri SL, Hansen HC, Deer TR, Abdi S, Jasper JF, Singh $V$, Jordan AE, Johnson BW, Cicala RS, Dunbar EE, Helm II S, Varley KG, Suchdev PK, Swicegood JR, Calodney AK, Ogoke BA, Minore WS, Manchikanti L.
Opioid guidelines in the management of chronic non-cancer pain. Pain Physician 2006; 9:1-40.

6. Bollinger LC, Bush C, Califano JA, Chenault KI, Curtis JL, Dimon J, Dolan PR, Ganzi VF, Fisher M, Kelmenson LA, Keough DR, Kessler DA, Malloy EA, Pacheco MT, Plumeri II JJ, Redstone SE, Rosenwald Jr EJ, Schulhof MP, Sullivan LW, Sweeney JJ, Wiener MA. Under the counter. The diversion and abuse of controlled prescription drugs in the U.S. The National Center on Addition and Substance Abuse at Columbia University (CASA), July 2005.

7. Substance Abuse and Mental Health Services Administration. (2007). Results from the 2006 National Survey on Drug Use and Health: National Findings. (Office of Applied Studies, NSDUH Series H-32, DHHS Publication No. SMA 07-4293). Rockville, MD. www.oas. samhsa.gov

8. Zacny J, Bigelow G, Compton P, Foley K, Iguchi M, Sannerud C. College on Problems of Drug Dependence taskforce on prescription opioid non-medical use and abuse: Position statement. Drug Alcohol Depend 2003; 69:215-232.

9. Manchikanti L, Giordano J, Boswell MV,
Fellows B, Manchukonda R, Pampati V. Psychological factors as predictors of opioid abuse and illicit drug use in chronic pain patients. J Opioid Manage 2007; 3:89-100.

10. Manchikanti L, Cash KA, Damron KS, Manchukonda R, Pampati V, McManus CD. Controlled substance abuse and illicit drug use in chronic pain patients: An evaluation of multiple variables. Pain Physician 2006; 9:215-226.

11. Manchikanti L, Manchukonda R, Damron KS, Brandon D, McManus CD, Cash $K A$. Does adherence monitoring reduce controlled substance abuse in chronic pain patients? Pain Physician 2006; 9:57-60.

12. Manchikanti L, Manchukonda R, Pampati V, Damron KS. Evaluation of abuse of prescription and illicit drugs in chronic pain patients receiving short-acting (hydrocodone) or long-acting (methadone) opioids. Pain Physician 2005; 8:257-261.

13. Manchikanti L. Screening for controlled substance abuse. Pain Physician 2004; 7:170.

14. Manchikanti L, Damron KS, McManus CD, Barnhill RC. Patterns of illicit drug use and opioid abuse in patients with 
chronic pain at initial evaluation: A prospective, observational study. Pain Physician 2004; 7:431-437.

15. Manchikanti L, Damron KS, Pampati V, MCManus CD, Weaver SE. Prospective evaluation of patients with increasing opiate needs: Prescription opiate abuse and illicit drug use. Pain Physician 2004; 7:339-344

16. Chelminski PR, Ives TJ, Felix KM, Prakken SD, Miller TM, Perhac JS, Malone RM, Bryant ME, DeWalt DA, Pignone MP. A primary care, multi-disciplinary disease management program for opioid-treated patients with chronic noncancer pain and a high burden of psychiatric comorbidity. BMC Health Serv Res 2005; 5:3.

17. Katz NP, Sherburne S, Beach M, Rose RJ, Vielguth J, Bradley J, Fanciullo GJ. Behavioral monitoring and urine toxicology testing in patients receiving long-term opioid therapy. Anesth Analg 2003; 97:1097-1102.

18. Katz NP, Adams EH, Benneyan JC, Birnbaum HG, Budman SH, Buzzeo RW, Carr DB, Cicero TJ, Gourlay D, Inciardi JA, Joranson DE, Kesslick J, Lande SD. Foundations of opioid risk management. Clin J Pain 2007; 23:103-118.

19. Stratton K, Howe C, Battaglia F. Fetal Alcohol Syndrome: Diagnosis, Epidemiology, Prevention, and Treatment. Institute of Medicine, National Academy Press, Washington, D.C., 1996.

20. Diagnostic and Statistical Manual of Mental Disorders DSM-IV-TR, Fourth Edition, American Psychiatric Association, 1994.

21. World Health Organization. WHO Expert Committee on Drug Dependence. 28th report. Geneva, Switzerland: WHO 1993.

22. World Health Organization. WHO Expert Committee on Drug Dependence. 3oth report. Geneva, Switzerland: WHO 1998.

23. The Controlled Substances Act (CSA), Title II and Title III of the Comprehensive Drug Abuse Prevention and Control Act of 1970.

24. World Health Organization. The ICD-10 Classification of Mental and Behavioral Disorders: Clinical Descriptions and Diagnostic Guidelines. Geneva, Switzerland: WHO, 1992.

25. American Academy of Pain Medicine (AAPM), the American Pain Society (APS), and the American Society of Addiction Medicine (ASAM). Definitions
Related to the Use of Opioids for the Treatment of Pain (Clarifications of "Addiction"). Feb. 2001.

www.painmed.org/pdf/definition.pdf

26. Savage SR. Assessment for addiction in pain-treatment settings. Clin J Pain 2002; 18:S28-S38.

27. Smith HS, Kirsh KL. Documentation and potential tools in long-term opioid therapy for pain. Med Clin North Am 2007; 91:213-228.

28. Højsted J, Sjøgren P. Addiction to opioids in chronic pain patients: A literature review. Eur J Pain 2007; 11:490518.

29. Friedman R, Li V, Mehrotra D. Treating pain patients at risk: Evaluation of a screening tool in opioid-treated pain patients with and without addiction. Pain Med 2003; 4:181-184.

30. Gavin DR, Ross HE, Skinner HA. Diagnostic validity of the drug abuse screening test in the assessment of DSM-III drug disorders. Br J Addict 1989; 84:301307.

31. Butler SF, Budman SH, Fernandez K, Jamison RN. Validation of a screener and opioid assessment measure for patients with chronic pain. Pain 2004; 112:65-75.

32. Passik SD, Kirsh KL, Whitcomb LA, Portenoy RK, Katz N, Kleinman L, Dodd $S$, Schein J. A new tool to assess and document pain outcomes in chronic pain patients receiving opioid therapy. Clin Ther 2004; 26:552-561.

33. Passik SD, Kirsh KL, Whitcomb LA, Schein JR, Kaplan M, Dodd S, Kleinman L, Katz NP, Portenoy RK. Monitoring outcomes during long-term opioid therapy for non-cancer pain: Results with the pain assessment and documentation tool. J Opioid Manage 2005; 1:257-266.

34. Webster LR, Webster RM. Predicting aberrant behaviors in opioid-treated patients: Preliminary validation of the Opioid Risk Tool. Pain Med 2005; 6:43242.

35. Etter M, Etter JF. Alcohol consumption and the CAGE test in outpatients with schizophrenia or schizoaffective disorder and in the general population. Schizophr Bull 2004; 30:947-956.

36. Chabal C, Erjavec MK, Jacobson L, Mariano A, Chaney E. Prescription opiate abuse in chronic pain patients: Clinical criteria, incidence, and predictors. Clin J Pain 1997; 13:150-155.

37. Brown RL, Rounds LA. Conjoint screening questionnaire for alcohol and drug abuse. Wisc Med J 1995; 94:135-140.

38. Miotto K, Compton P, Ling W, Conolly M. Diagnosing addictive disease in chronic pain patients. Psychosomatics 1996; 37:223-235.

39. Passik SD, Kirsh KL, McDonald MV, Ahn S, Russak SM, Martin L, Rosenfeld B, Breitbart WS, Portenoy RK. A pilot survey of aberrant drug-taking attitudes and behaviors in samples of cancer and AIDS patients. J Pain Symptom Manage 2000; 19:274-286.

40. Cowan DT, Allan L, Griffiths P. A pilot study into the problematic use of opioid analgesics in chronic non-cancer pain patients. Int / Nurs Stud 2002; 39:59-69.

41. Cowan DT, Wilson-Barnett J, Griffiths P, Allan LG. A survey of chronic noncancer pain patients prescribed opioid analgesics. Pain Med 2003; 4:340-351.

42. Cowan DT, Allan LG, Libretto SE, Griffiths P. Opioid drugs: A comparative survey of therapeutic and "street" use. Pain Med 2001; 2:193-203.

43. Adams LL, Gatchel RJ, Robinson RC, Polatin P, Gajraj N, Deschner M, Noe C. Development of a self-report screening instrument for assessing potential opioid medication misuse in chronic pain patients. J Pain Symptom Manage 2004; 27:440-459.

44. Elander J, Lusher J, Bevan D, Telfer P. Pain management and symptoms of substance dependence among patients with sickle cell disease. Soc Sci Med 2003; 57:1683-1696.

45. Michna E, Ross EL, Hynes WL, Nedeljkovic SS, Soumekh S, Janfaza D, Palombi D, Jamison RN. Predicting aberrant drug behavior in patients treated for chronic pain: Importance of abuse history. J Pain Symptom Manage 2004; 28:250-258.

46. Butler SF, Budman SH, Fernandez KC, Houle B, Benoit C, Katz N, Jamison RN. Development and validation of the current opioid misuse measure. Pain 2007; 130:144-156.

47. Atluri SL, Sudarshan G. Development of a screening tool to detect the risk of inappropriate prescription opioid use in patients with chronic pain. Pain Physician 2004; 7:333-338.

48. Compton P, Darakjian MA, Miotto K. Screening for addiction in patients with chronic pain and "problematic" substance use: Evaluation of a pilot assessment tool. J Pain Symptom Manage 1998; 16:355-363. 
49. Coambs RE, Jarry JL, Santhiapillai AC, Abrahamsohn RV, Atance CM. The SISAP: A new screening instrument for identifying potential opioid abusers in the management of chronic nonmalignant pain in general medical practice. Pain Res Manage 1996; 1:155-162.

50. Schieffer BM, Pham Q, Labus J, Baria A, Van Vort W, Davis P, Davis F, Naliboff BD. Pain medication beliefs and medication misuse in chronic pain. J Pain 2005; 6:620-629.

51. Wu SM, Compton P, Bolus R, Schieffer B, Pham Q, Baria A, Van Vort W, Davis F, Shekelle P, Naliboff BD. The addiction behaviors checklist: Validation of a new clinician-based measure of inappropriate opioid use in chronic pain. $J$ Pain Symptom Manage 2006; 32:342351.

52. Akbik H, Butler SF, Budman SH, Fernandez K, Katz NP, Jamison RN. Validation and clinical application of the screener and opioid assessment for patients with pain (SOAPP). I Pain Symptom Manage 2006; 32:287-293.

53. Holmes CP, Gatchel RJ, Adams LL, Stowell AW, Hatten A, Noe C, Lou L. An opioid screening instrument: Long-term evaluation of the utility of the Pain Medication Questionnaire. Pain Pract 2006; 6:74-88.

54. Manchikanti L, Singh V, Damron KS, Beyer CD, Pampati V. Screening for controlled substance abuse in interventional pain management settings: Evaluation of an assessment tool. Pain Physician 2003; 6:425-433.

55. Manchikanti L, Pampati V, Damron KS, McManus CD. Evaluation of variables in illicit drug use: Does a controlled substance abuse screening tool identify illicit drug use? Pain Physician 2004; 7:71-75.

56. Cyr M, Wartman S. The effectiveness of routine screening questions in the detection of alcoholism. JAMA 1988; 259:51-54.

57. Skinner HA, Holt S, Schuller R, Roy J, Israel $Y$. Identification of alcohol abuse using laboratory tests and a history of trauma. Ann Intern Med 1984; 101:847851.

58. Sullivan E, Fleming M. A Guide to Substance Abuse Services for Primary Care Clinicians. Treatment Improvement Protocols, ed. U.S. Centers for Substance Abuse Treatment. Rockville, MD: U.S. Department of Health and Human Ser- vices, 1997

59. Portenoy RK. Opioid therapy for chronic nonmalignant pain: A review of the critical issues. J Pain Symptom Manage 1996; 11:203-217.

6o. Burke JD, Burke KC, Rae DS. Increased rates of drug abuse and dependence after onset of mood or anxiety disorders in adolescence. Hosp Community Psychiatry 1994; 45:451-455.

61. Christie KA, Burke JD Jr., Regier DA, Rae DS, Boyd JH, Locke BZ. Epidemiologic evidence for early onset of mental disorders and higher risk of drug abuse in young adults. Am. J. Psychiatry 1988; 145:971-975.

62. Ross HE, Glaser FB, Germanson T. The prevalence of psychiatric disorders in patients with alcohol and other drug problems. Arch. Gen. Psychiatry. 1988; 45:1023-1031.

63. Farrell $M$, Howes $S$, Bebbington $P$, Brugha T, Jenkins R, Lewis G, Marsden J, Taylor C, Meltzer H. Nicotine, alcohol and drug dependence and psychiatric comorbidity. Br J Psychiatry 2001; 179:432-437.

64. Regier DA, Farmer ME, Rae DS, Locke BZ, Keith SJ, Judd LL, Goodwin FK. Comorbidity of mental disorders with alcohol and other drug use. JAMA 1990; 264:2511-2518.

65. Webster L. Assessing abuse potential in pain patients. Medscape Neurol Neurosurg 2004; 6.

66. Ives TJ, Chelminski PR, Hammett-Stabler CA, Malone RM, Perhac JS, Potisek NM, Shilliday BB, DeWalt DA, Pignone MP. Predictors of opioid misuse in patients with chronic pain: A prospective cohort study. BMC Health Serv Res 2006; 6:46

67. Dersh J, Gatchel RJ, Mayer T, Polatin P, Temple OR. Prevalence of psychiatric disorders in patients with chronic disabling occupational spinal disorders. Spine 2006; 31:1156-1162.

68. Manchikanti L, Pampati V, Damron KS, Fellows B, Barnhill RC, Beyer CD. Prevalence of opioid abuse in interventional pain medicine practice settings: A randomized clinical evaluation. Pain Physician 2001; 4:358-365.

69. Manchikanti L, Pampati V, Damron K, Beyer CD, Barnhill RC. Prevalence of illicit drug use in patients without controlled substance abuse in interventional pain management. Pain Physi- cian 2003; 6:173-178.

70. Manchikanti L, Beyer C, Damron K, Pampati V. A comparative evaluation of illicit drug use in patients with or without controlled substance abuse in interventional pain management. Pain Physician 2003; 6:281-285.

71. Manchikanti L, Damron KS, Pampati V, McManus CD. Prevalence of illicit drug use among individuals with chronic pain in the Commonwealth of Kentucky: An evaluation of patterns and trends. J Ky Med Assoc 2005; 103:5562.

72. Manchikanti L, Pampati V, Damron KS, Beyer CD, Barnhill RC, Fellows B. Prevalence of prescription drug abuse and dependency in patients with chronic pain in western Kentucky. J KY Med Assoc 2003; 101:511-517.

73. Manchikanti L, Manchukonda R, Pampati V, Damron KS, Brandon DE, Cash $\mathrm{KA}$, McManus CD. Does random urine drug testing reduce illicit drug use in chronic pain patients receiving opioids? Pain Physician 2006; 9:123-129.

74. Wallace LS, Keenum AJ, Roskos SE. Comprehensibility and readability of patient self-administered opioid assessment screening tools. J Opioid Manage 2007; 3:338-344.

75. Caplan YH, Goldberger BA. Alternative specimens for workplace drug testing. J Anal Toxicol 2001; 25:396-399.

76. Gourlay DL, Caplan YH, Heit HA. Urine Drug Testing in Clinical Practice: Dispelling the Myths and Designing Strategies. Edition 3, 2006.

77. Hammett-Stabler CA, Pesce AJ, Cannon DJ. Urine drug screening in the medical setting. Clin Chim Acta 2002; 315:125135.

78. Code of Federal Regulations. 49 CFR \$40. Office of the Federal Register. 1998. www.access.gpo.gov/nara/cfr/ cfr-table-search.html

79. Simpson D, Braithwaite RA, Jarvie DR, Stewart MJ, Walker S, Watson IW, Widdop B. Screening for drugs of abuse (II): Cannabinoids, lysergic acid diethylamide, buprenorphine, methadone, barbiturates, benzodiazepines and other drugs. Ann Clin Biochem 1997; 34:460-510.

80. Office of National Drug Control Policy. What You Need to Know About Drug Testing in Schools. 2002. www.whitehousedrugpolicy.gov/pdf/ 
drug testing.pdf

81. Cone EJ. New developments in biological measures of drug prevalence. Chemistry and Drug Metabolism Section. Addiction Research Center. National Institute on Drug Abuse.

82. Peine SI. A Closer Look at State Prescription Monitoring Programs. Washington, D.C., Drug Enforcement Administration, 2000.

www.deadiversion.usdoj.gov/pubs/ program/rx_monitor/index.html

83. Alliance for Model State Drug Laws and National Association of State Controlled Substance Authorities, 1999.

84. Simeone R, Holland L. An Evaluation of Prescription Monitoring Programs. U.S.
Department of Justice, Office of Justice Programs, Bureau of Justice Assistance, 2006.

85. National All Schedules Prescription Electronic Reporting Act of 2005: A review of implementation of existing state controlled substance monitoring programs. Center for Substance Abuse Treatment, Substance Abuse and Mental Health Services Administration, US Department of Health and Human Services. October 2007.

86. NASPER Act of 2005: A review of implementation of existing state controlled substance monitoring programs. Center for Substance Abuse Treatment, SAMHSA, US Department of HHS. October 2007.
87. Brushwood DB. Maximizing the value of electronic prescription monitoring programs. J Law, Med Ethics 2003; 31:41-54.

88. Twillman R. Impact of prescription monitoring programs on prescription patterns and indicators of opioid abuse. J Pain 2006, 7:S6.

89. Department of Health Professions and Virginia State Police, 2004, pages iv-v.

90. Barrett K, Watson A. Physician perspectives on a pilot prescription monitoring program. J Pain Palliat Care Pharmacother 2005; 19:5-13.

91. Fagan MJ, Chen JT, Diaz JA, Reinert SE, Stein MD. Do internal medicine residents find pain medication agreements useful? Clin J Pain 2008; 24:35-38. 